\title{
Kinetics of Cyclophosphamide Metabolism in Humans, Dogs, Cats, and Mice and Relationship to Cytotoxic Activity and Pharmacokinetics ${ }^{\mathbb{S}}$
}

\author{
D Dominique A. Ramirez, Keagan P. Collins, Allister E. Aradi, Katherine A. Conger, \\ and Daniel L. Gustafson

\begin{abstract}
Department of Clinical Sciences (D.A.R., A.E.A., D.L.G.) and School of Biomedical Engineering (K.P.C., K.A.C., D.L.G.), Colorado State University, Fort Collins, and University of Colorado Cancer Center, Aurora (D.L.G.), Colorado
\end{abstract}

Received July 31, 2018; accepted December 12, 2018

\begin{abstract}
Cyclophosphamide (CP), a prodrug that is enzymatically converted to the cytotoxic 4-hydroxycyclophosphamide (4OHCP) by hepatic enzymes, is commonly used in both human and veterinary medicine to treat cancers and modulate the immune system. We investigated the metabolism of CP in humans, dogs, cats, and mice using liver microsomes; apparent $K_{\mathrm{M}}, V_{\max }$, and intrinsic clearance $\left(V_{\max } / K_{\mathrm{M}}\right)$ parameters were estimated. The interspecies and intraspecies variations in kinetics were vast. Dog microsomes were, on average, 55-fold more efficient than human microsomes, 2.8-fold more efficient than cat microsomes, and 1.2-fold more efficient than mouse microsomes at catalyzing CP bioactivation. These differences translated to cell-based systems. Breast cancer cells exposed to $40 \mathrm{HCP}$ via CP bioactivation by microsomes resulted in a
\end{abstract}

stratification of cytotoxicity that was dependent on the species of microsomes measured by $I_{50}$ : $\operatorname{dog}(31.65 \mu \mathrm{M})$, mouse $(44.95 \mu \mathrm{M})$, cat $(272.6 \mu \mathrm{M})$, and human $(1857 \mu \mathrm{M})$. The contributions of cytochrome P450s, specifically, CYP2B, CYP2C, and CYP3A, to CP bioactivation were examined: CYP3A inhibition resulted in no change in 4OHCP formation; CYP2B inhibition slightly reduced 4OHCP in humans, cats, and mice; and CYP2C inhibition drastically reduced $40 H C P$ formation in each species. Semiphysiologic modeling of CP metabolism using scaled metabolic parameters resulted in simulated data that closely matched published pharmacokinetic profiles, determined by noncompartmental analysis. The results highlight differential CP metabolism delineated by species and demonstrate the importance of metabolism on CP clearance.

\section{Introduction}

Cyclophosphamide (CP) is an oxazaphosphorine antineoplastic agent used to treat a variety of hematopoietic and solid tumors in both human and veterinary medicine. It is also used as an immunosuppressant for some autoimmune diseases and for immunoablation in bone marrow transplants (Ahmed and Hombal, 1984; Emadi et al., 2009). CP can be dosed intravenously or orally on a variety of schedules, depending on the application. Typical chemotherapeutic doses in humans are 500 $1200 \mathrm{mg} / \mathrm{m}^{2}$ cumulatively when administered every 21 days either as a single dose or fractionated over multiple doses (de Jonge et al., 2005; Penel et al., 2012). Chemotherapeutic doses of CP in dogs and cats range from 200 to $250 \mathrm{mg} / \mathrm{m}^{2}$ (Garrett et al., 2002; Warry et al., 2011) and from 200 to $300 \mathrm{mg} / \mathrm{m}^{2}$ (Teske et al., 2002; Stroda et al., 2017), respectively, and are reflective of the University of Wisconsin-Madison protocol

This work was supported by the Shipley University Chair in Comparative Oncology and the Angelo Fund for Feline Therapeutics, and by the Pharmacology Shared Resource for the University of Colorado Cancer Center, which is funded by the National Institutes of Health National Cancer Institute [Grant P30 CA046934]. Support for animal studies was provided by the University of Colorado Cancer Center Pharmacology Shared Resource [Grant P30CA046934]. https://doi.org/10.1124/dmd.118.083766.

S This article has supplemental material available at dmd.aspetjournals.org. and its variations. The doses used in humans, dogs, and cats are empirically determined from the maximum tolerated dose in each of the species with sparse historical pharmacokinetic data available for comparison owing to the complex nature of $\mathrm{CP}$ pharmacology. $\mathrm{CP}$, a prodrug, requires metabolic activation to 4-hydroxycyclophosphamide (4OHCP) for initiation of a spontaneous breakdown cascade (Fig. 1) resulting in the generation of the putative cytotoxic phosphoramide mustard (PM) capable of bifunctional alkylation (Groehler et al., 2016) and acrolein, which causes varying degrees of bladder toxicity (Moghe et al., 2015). The conversion of CP to $4 \mathrm{OHCP}$ is believed to happen only in the liver, as opposed to occurring directly in cancer cells (Boddy and Yule, 2000), and the production of 4OHCP is dependent on hepatic enzymes, namely, the cytochrome P450 (P450) superfamily (Bagley et al., 1973; Li et al., 2010).

The complex sequelae associated with hepatic production of reactive metabolites that must traverse from the liver through the blood to target tumor cells for antineoplastic activity, or normal tissues for toxicity, have made pharmacokinetic-pharmacodynamic relationships for CP difficult to define. Early in vitro cytotoxicity bioassays relied on treating cells with plasma from humans or animals dosed with CP (Stevenson and Fauci, 1980). After improvements in chemical synthesis and liver microsome isolation methods, contemporary scientists studying $\mathrm{CP}$ in vitro have the option of using other bioactivation strategies or commercially available PM precursors, such as the peroxide 4-hydroperoxycyclophosphamide, that do

ABBREVIATIONS: 4OHCP, 4-hydroxycyclophosphamide; 4OHCP-SCZ, 4-hydroxycyclophosphamide semicarbazone; AUC, area under the curve; C, cat; CBP, 4-(4-chlorobenzyl)-pyridine; $\mathrm{CL}_{\text {int }}$, intrinsic clearance; $\mathrm{CP}$, cyclophosphamide; D, dog; H, human; HB, homogenization buffer; HMP, hexamethylphosphoramide; LC-MS/MS, liquid chromatography tandem mass spectrometry; M, mouse; P450, cytochrome P450; PK, pharmacokinetics; PM, phosphoramide mustard. 


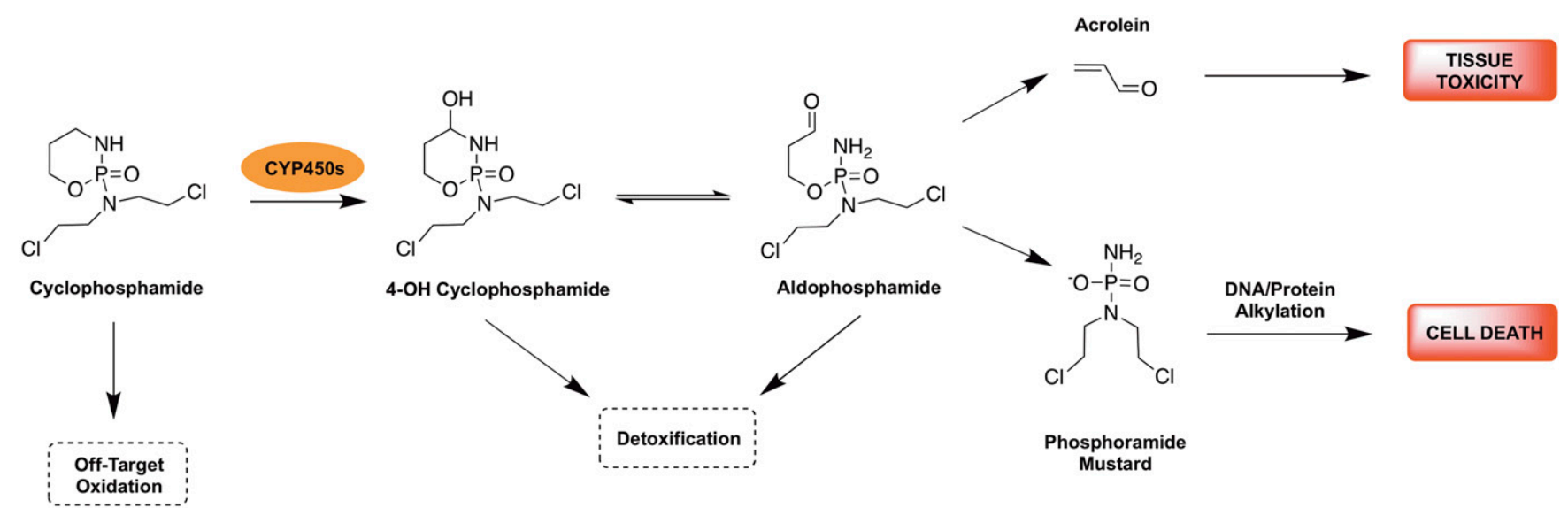

Fig. 1. Schematic of CP biotransformation.

not require enzymatic activation. Additionally, improvements in techniques that trap transient metabolic intermediates have permitted better and more sensitive quantification of CP from biologic matrices (Huitema et al., 2000).

Recently, in concordance with improved methods for liver microsome isolation and supersome production, human-oriented $\mathrm{CP}$ research has identified important molecular components responsible for CP metabolism (Roy et al., 1999; Huang et al., 2000; Kumar et al., 2007). In humans, these molecular components are known to vary widely between individuals on an expression and polymorphism basis (Zanger and Schwab, 2013). Numerous human P450 isoforms have been implicated in the bioactivation of CP, namely, CYP2B6, CYP3A4, CYP2C9, and CYP2C19 (Rodriguez-Antona and Ingelman-Sundberg, 2006), but CYP2B6 is hypothesized to be the putative critical enzyme responsible for 4OHCP formation (Xie et al., 2003). These studies complement the growing canon of $\mathrm{CP}$ research in humans that includes in vitro, in vivo, and pharmacokinetic (PK) work. In contrast, most published CP-related research in the veterinary field is clinical, and a gap persists in pharmacologic and molecular knowledge. Because animal surrogates for human cancers are vital translational models for cancer research and pharmacology, animal cancer research is equally key for the progression of clinical veterinary medicine and improving comparative oncology, even for a drug as well established in the clinic as CP.

This study investigated steady-state kinetics of CP bioactivation by hepatic microsomes in three species frequently treated with $\mathrm{CP}-$ humans, dogs, and cats - and in the traditional preclinical animal model, the mouse. These data identified significant metabolic differences between the species' apparent kinetic parameters $K_{\mathrm{M}}$ and $V_{\max }$.
In vitro application of these data revealed predictable cytotoxic responses dependent on the kinetics of CP activation. Using these data in silico to compare retrospectively prior CP PK data to those simulated based purely on scaled metabolic parameters suggests that hepatic $\mathrm{CP}$ activation, coupled with liver blood flow and protein binding, primarily drives $\mathrm{CP}$ clearance in humans, dogs, cats, and mice.

\section{Materials and Methods}

Chemicals. Cyclophosphamide monohydrate, hexamethylphosphoramide, semicarbizide hydrochloride, sulfaphenazole, and anhydrous EDTA were purchased from Sigma-Aldrich (St. Louis, MO). 4-Hydroperoxycyclophosphamide, a precursor to 4-hydroxycyclophosphamide, was purchased from Niomech-IIT GmbH (Bielefeld, Germany); 4-(4-chlorobenzyl)pyridine and fluconazole were purchased from TCI Chemicals (Portland, OR). Miconazole and chloramphenicol were purchased from MP Biomedicals (Solon, $\mathrm{OH}$ ). Ketoconazole was purchased from Acros Organics (Morris Plains, NJ). $\beta$-NADPH tetrasodium salt was purchased from Roche Life Science (Indianapolis, IN), and Gentest NADPH Regenerating System components were purchased from Corning (Corning, NY). Potassium phosphate dibasic anhydrous, potassium phosphate monobasic, and molecular grade D-sucrose were purchased from Fisher Scientific (Waltham, MA). Acetonitrile and other solvents used for liquid chromatography-tandem mass spectrometry (LC-MS/MS) are of ultra-performance liquid chromatography-MSgrade and were purchased from Fisher Scientific.

Microsome Sources and Preparation. Microsomes used in this study include commercially available and freshly isolated batches. Source information for microsomes used in this study is listed in Table 1. Isolated microsomes were prepared by differential centrifugation from liver samples either from freshly harvested liver sections or from liver samples that had been stored frozen at $-80^{\circ} \mathrm{C}$.

TABLE 1

Source information for each batch of microsomes used in the study

\begin{tabular}{|c|c|c|c|c|c|c|}
\hline ID & Species & Production & Lot/Batch & Sex & Age & Pool Size \\
\hline H1 & Human & XenoTech (H0620) & 1610016 & Mixed & Mixed & 50 \\
\hline $\mathrm{H} 2$ & Human & Corning (452161) & 6123001 & Mixed & Mixed & 33 \\
\hline H3 & Human & Gibco (HMMCPL) & PL050B & Mixed & Mixed & 50 \\
\hline $\mathrm{D} 1^{a}$ & Canine, Labrador & Laboratory-made & & Female & $2 \mathrm{yr}$ & 4 \\
\hline $\mathrm{D} 2^{b}$ & Canine, Labrador & Laboratory-made & & Male & $14 \mathrm{yr}$ & 1 \\
\hline $\mathrm{D}^{a}$ & Canine, hound & Laboratory-made & & Female & $10 \mathrm{mo}$ & 5 \\
\hline D4 & Canine, beagle & XenoTech (D1500) & 1310105 & Female & Mixed (4-9 yr) & 12 \\
\hline $\mathrm{C} 1^{b}$ & Feline, mixed breed & Laboratory-made & & Mixed & Mixed & 4 \\
\hline $\mathrm{C} 2$ & Feline, short hair & XenoTech (F1000) & 0610343 & Male & Sexually mature & 3 \\
\hline $\mathrm{M} 1^{a}$ & Mouse, NIH CD1 Swiss & Laboratory-made & & Female & $6 \mathrm{wk}$ & 5 \\
\hline $\mathrm{M} 2^{a}$ & Mouse, NIH CD1 Swiss & Laboratory-made & & Female & Mixed & 3 \\
\hline M3 & Mouse, NIH CD1 Swiss & XenoTech (M1500) & 1410027 & Female & Mixed & 990 \\
\hline
\end{tabular}

${ }^{a}$ Microsomes were prepared immediately from freshly harvested liver samples.

${ }^{b}$ Microsomes were prepared from liver samples that were frozen upon receipt. 
Freshly harvested liver sections were kept on ice for immediate microsome processing. Liver pieces that had to be frozen were kept below $25^{\circ} \mathrm{C}$, on ice until they could be transferred into tubes for storage at $-80^{\circ} \mathrm{C}$ and were not thawed until microsome isolation. Storage of liver at $-80^{\circ} \mathrm{C}$ has been shown not to result in loss of P450 in liver samples (Yamazaki et al., 1997). All steps of the isolation were performed at $4{ }^{\circ} \mathrm{C}$ or on ice. Liver sections were first homogenized in homogenization buffer (HB: $100 \mathrm{mM}$ D-sucrose, $1 \mathrm{mM}$ EDTA) with a dounce homogenizer fitted to a handheld power drill at a 100-mg liver-weight/milliliter $\mathrm{HB}$ ratio. Homogenates were subjected to the following differential centrifugation scheme: $800 \mathrm{~g}$ for 10 minutes, $7000 \mathrm{~g}$ for 10 minutes, and $18,000 \mathrm{~g}$ for 5 minutes. After each spin, the supernatant was transferred to a new centrifuge tube, and the pellet was discarded. After the $18,000 \mathrm{~g}$ spin, the supernatant was spun at $100,000 \mathrm{~g}$ for 1 hour. The supernatant was discarded, and the pellet containing microsomes was resuspended gently in $\mathrm{HB}$ in a volume ranging from 100 to $400 \mu \mathrm{l}$. Microsomes were then stored at $-80^{\circ} \mathrm{C}$, and an aliquot was used to determine total protein concentration via the BCA assay in duplicate (Thermo Scientific, Waltham, MA). Microsome aliquots were thawed on ice for incubation and kinetics experiments and were not used after three freeze/thaw cycles, in line with published data on P450 stability (Pearce et al., 1996).

Microsome Incubations. Microsomes were incubated to determine optimal reaction conditions (concentration of microsomal protein and incubation time) for downstream kinetics assays. Reactions were prepared with microsomes $(0.5 \mathrm{mg} / \mathrm{ml})$ and $1.0 \mathrm{mM}$ NADPH (solvated in $0.1 \mathrm{M}$ phosphate buffer) in $0.1 \mathrm{M}$ phosphate buffer $\left(44 \mathrm{mM} \mathrm{KH}_{2} \mathrm{PO}_{4}, 56 \mathrm{mM} \mathrm{K}_{2} \mathrm{HPO}_{4}, \mathrm{pH} 7.4\right.$, and adjusted with $\mathrm{NaOH}$ ). A reaction master mix was prepared without substrate and preincubated at $37^{\circ} \mathrm{C}$ for 5 minutes; then it was initiated by the addition of substrate $(2 \mu \mathrm{g} / \mathrm{ml} \mathrm{CP})$ and incubated at $37^{\circ} \mathrm{C}$. At specific time points $(0,5,10,20$, 30, 45, 60 minutes), $100 \mu \mathrm{l}$ of sample was removed from the master mix and stopped with an equal volume of acetonitrile and chilled on wet ice, and $2 \mathrm{M}$ semicarbizide hydrochloride (SCZ) (1:10 dilution into sample, final $\sim 0.2 \mathrm{M}$ ) was immediately added to trap 4OHCP (4OHCP-SCZ) and prevent spontaneous breakdown (Warry et al., 2011). Samples were either frozen for later use or prepared immediately for LC-MS/MS analysis. Storage at $-80^{\circ} \mathrm{C}$ for up to 12 months after semicarbizide trapping does not affect the stability of the 4OHCP metabolite (Huitema et al., 2000). Each incubation was performed in a technical singlet. Protein concentration was increased to $1.0 \mathrm{mg} / \mathrm{ml}$, and the incubations were repeated if insignificant $4 \mathrm{OHCP}$ formation was observed at $0.5 \mathrm{mg} / \mathrm{ml}$.

Michaelis-Menten kinetic assays were performed by incubating microsomes with cyclophosphamide using a discontinuous method. Individual reactions at each CP concentration were performed as technical singlets. Reactions were prepared with microsomes with an NADPH regenerating system (ensuring $\sim 1.3 \mathrm{mM}$ NADPH) in $0.1 \mathrm{M}$ phosphate buffer. Reactions were prepared without substrate and preincubated at $37^{\circ} \mathrm{C}$ for 5 minutes. Reactions were initiated by the addition of substrate and incubated at $37^{\circ} \mathrm{C}$ for the duration of the reaction. Reaction times and specific microsome concentrations for each species, determined from incubations described herein, used for kinetics experiments are as follows: human (20 minutes, $1.0 \mathrm{mg} / \mathrm{ml}$ protein), dog (5 minutes, $0.5 \mathrm{mg} / \mathrm{ml}$ protein), cat (10 minutes, $0.5 \mathrm{mg} / \mathrm{ml}$ protein), and mouse ( 5 minutes, $0.5 \mathrm{mg} / \mathrm{ml}$ protein). These conditions were chosen because they demonstrated linear product formation with respect to time (data not shown). Reactions were stopped using the same method as described already. Samples were then either frozen for later analysis or prepared immediately for LC-MS/MS.

We selected $0.5 \mathrm{mg} / \mathrm{ml}$ microsomal protein as the optimal starting concentration for our incubations, in accordance with published methods and guidelines for performing enzyme kinetics assays (Jia and Liu, 2007; Vrbanac and Slauter, 2013). Two different sources of NADPH were used as described herein, depending on the type of assay. Stability tests performed inhouse suggest that NADPH is unstable but is usable in incubations for up to 30 minutes at $37^{\circ} \mathrm{C}$ in water and phosphate buffer (data not shown). In assays that did not require lengthy incubations, such as the discontinuous kinetics assays, NADPH salt was used. For assays that required incubation times up to and beyond 30 minutes, the regenerating system was used.

Cytochrome P450 Inhibition Assays. Microsomes were incubated with CP and different P450 inhibitors to determine the contribution of certain P450 isozymes in the metabolism of CP. The following inhibitors were used at the listed concentrations: 4-(4-chlorobenzyl)pyridine (CBP) at $1 \mu \mathrm{M}$ targeting CYP2B6 (Korhonen et al., 2007); ketoconazole at $1 \mu \mathrm{M}$ targeting CYP3A4 (Eagling et al., 1998; Kuroha et al., 2002); fluconazole at $25 \mu \mathrm{M}$ targeting CYP2C9 (Back et al.,
1988; Miners and Birkett, 1998); and miconazole at $1 \mu \mathrm{M}$ targeting CYP2C19 (Niwa et al., 2005). Fluconazole can also inhibit CYP3A4 (Kunze et al., 1996), similarly to miconazole (Sakaeda et al., 2005). Additionally, chloramphenicol at $10 \mu \mathrm{M}$ targeting canine CYP2B11 and sulfaphenazole at $100 \mu \mathrm{M}$ targeting canine CYP2C21/41 have been identified (Perez Jimenez et al., 2018) and were included for the dog microsome only. The concentrations selected are higher than published $\mathrm{IC}_{50}$ values to ensure adequate inhibition of respective $\mathrm{P} 450 \mathrm{~s}$. Inhibitors were prepared in methanol but were diluted in phosphate buffer such that the organic concentration would be $<1 \%$ after the final addition into reaction mixtures.

Reaction master mixes were prepared with microsomes, an NADPHregenerating system (ensuring $\sim 1.3 \mathrm{mM} \mathrm{NADPH}$ ), $0.5 \mathrm{mg} / \mathrm{ml}$ microsomal protein, and inhibitor in $0.1 \mathrm{M}$ phosphate buffer. Reactions were preincubated at $37^{\circ} \mathrm{C}$ for 10 minutes to account for any mechanism-based inactivation of $\mathrm{P} 450 \mathrm{~s}$. Reactions were initiated with the addition of $2 \mu \mathrm{g} / \mathrm{ml} \mathrm{CP}$ and at specified time points $(0,5,10,15,30,60,90,120$ minutes), $100 \mu$ l was removed, and the reaction was stopped using the same method as described already. Samples were then either frozen or prepared immediately for analysis of 4OHCP and CP by LC-MS/MS. Inhibition experiments as described were done in singlet. Quantified 4OHCP concentration (in micromolars) at every time point, for each condition, was normalized to the initial quantified CP concentration (in micromolars) and plotted. Area under the curve (AUC) for each normalized 4OHCP versus time curve was calculated using the trapezoidal method implemented in GraphPad Prism 7.0d (GraphPad Software Inc., La Jolla, CA). AUC from each condition was then normalized again, this time to the control condition (microsomes with $\mathrm{CP}$ only, labeled $+C P$ ).

LC-MS/MS Analysis. Samples were processed for analysis via LC-MS/MS by a modification of a previously described method (Warry et al., 2011). In cases where substrate exceeded $100 \mu \mathrm{g} / \mathrm{ml}$, samples were diluted by a factor of 100 . Dilution quality controls were used to validate the dilutions as analytically appropriate. Samples for LC-MS/MS analysis were prepared fresh or thawed if frozen. Hexamethylphosphoramide (HMP, internal standard) was spiked into each sample at a final concentration of $500 \mathrm{ng} / \mathrm{ml}$, and samples were vortexed for 5 minutes. Samples were centrifuged at $20,000 \mathrm{~g}$ for 5 minutes, and the supernatant was collected for analysis. Positive ion electrospray ionization mass spectra were obtained with an Applied Biosystems SCIEX 3200 QTRAP (SCIEX LLC, Framingham, MA) triple-quadrupole MS with a TurboIonSpray source interfaced to a Shimadzu Prominence high-performance liquid chromatography system (Shimadzu Scientific Instruments Inc., Columbia, MD) and a CTC Analytics HTC PAL System autosampler (CTC Analytics, Lake Elmo, MN). Samples were chromatographed with a Waters SunFire C18 $5 \mu \mathrm{m}, 4.6 \times 50-\mathrm{mm}$ column (Waters Corp., Milford, MA) protected by a Security-Guard C18 cartridge (Phenomenex, Torrence, CA). Ammonium acetate $(10 \mathrm{mM}, \mathrm{pH} 8.0$, adjusted with $\mathrm{NH}_{4} \mathrm{OH}$ ) was solvent $\mathrm{A}$, and acetonitrile was solvent $\mathrm{B}$. Chromatographic separation was accomplished in 6 minutes at a flow rate of $440 \mu \mathrm{l} / \mathrm{min}$ using the following gradient: minute $0.0,10 \% \mathrm{~B}$; minute $1.0,10 \% \mathrm{~B}$; minute $3.0,60 \% \mathrm{~B}$; minute $4.0,60 \% \mathrm{~B}$; minute $4.5,10 \% \mathrm{~B}$. Analytes were quantified via multiple reaction monitoring of the ion transitions for 4OHCP-SCZ, CP, and HMP. Nitrogen gas was used as the collision gas. Three ion transitions for 4OHCP-SCZ were monitored and summed into one peak for analysis: $\mathrm{m} / \mathrm{z} 334.3 \rightarrow 221.3, \mathrm{~m} / \mathrm{z}$ $334.3 \rightarrow 259.3$, and $m / z, 334.3 \rightarrow 114.3$. These three peaks were incorporated into the final method, as opposed to using a single transition, as the sum of these three peaks greatly improved sensitivity and detection of $4 \mathrm{OHCP}$ from biologic matrices. CP was monitored as $m / z 261.2 \rightarrow 140.2$. HMP was monitored as $m / z$ $180.0 \rightarrow 135.0$. The chromatographic peaks associated with 4OHCP-SCZ, CP, and HMP were integrated and the concentrations of the samples were based on the ratio of analyte:internal standard using Analyst (AB SCIEX LLC) software.

Kinetics Analysis. Michaelis-Menten parameters were determined for each microsome source after incubations (listed above), performed in singlet. Formation of product (4OHCP-SCZ) was determined absolutely with LC-MS/MS and converted to velocity (pmol $4 \mathrm{OHCP} / \mathrm{min}$ per milligram protein). GraphPad Prism 7.0d analysis software was used to estimate the Michaelis-Menten parameters. Specific CP concentrations used to estimate the kinetic parameters varied between microsome batches, but in no case were any data points excluded from the Michaelis-Menten curves. Velocity-substrate data were transformed using Eadie-Hoftsee linearization to assess the quality of the experiments, where the case of nonlinearity suggests poor experimental design, execution, and/or a multiple enzyme model (Supplemental Fig. 1). 
Cell Culture. MDA-MB-231 human mammary epithelial tumor cells were purchased from American Type Culture Collection (Manassas, CA) and maintained in Ham's F-12 modified media (10-080-CV; Corning) supplemented with $10 \%$ fetal bovine serum, $1 \mathrm{mM}$ sodium pyruvate, $100 \mathrm{U}$ of penicillin, and $100 \mu \mathrm{g} / \mathrm{ml}$ streptomycin, and grown at $37^{\circ} \mathrm{C}$ and $5 \% \mathrm{CO}_{2}$. Cells were verified to be mycoplasma-free via PCR (Uphoff and Drexler, 2013) before transduction with IncuCyte NucLight Red lentiviral system (Essen BioScience Inc., Ann Arbor, MI) under puromycin selection to stably express nuclear-localized red fluorescent protein.

Cytotoxicity Assays. NucLight Red-labeled MDA-MB-231 cells were plated into 96-well plates in supplemented Ham's F-12 media at a density to ensure midto late-log phase growth between 72 and 76 hours after plating. Cells were treated with microsomes and cyclophosphamide to mimic in vivo metabolism of CP to its active metabolite. Two different controls were tested in the development of the cytotoxicity assay, one being cells exposed neither to $\mathrm{CP}$ nor microsomes, and the second being cells exposed to microsomes but not $\mathrm{CP}$ for the duration of the experiment. The first control verified that there were no volatile metabolites formed during the assay that could contaminate other wells (data not shown), and thus for each subsequent assay, only the second control was used. Reaction mixtures containing microsomes $(1.0 \mathrm{mg} / \mathrm{ml}), \mathrm{CP}(3.8-3831 \mu \mathrm{M})$, and an NADPH- regenerating system in supplemented Ham's F12 media were placed directly on top of cells in each well at a final volume of $0.2 \mathrm{ml}$ and incubated at $37^{\circ} \mathrm{C}$ and $5 \% \mathrm{CO}_{2}$ for 2 hours. The incubation time was selected to represent the pharmacologic half-life of $\mathrm{CP}$ but is a compromise between the wide range of reported half-lives for each species. After the incubation period, cells were washed once with Hanks' balanced salt solution (21-021-CV; Corning), and then supplemented Ham's F12 media were refreshed in each well. Nuclear fluorescence was monitored every 3 hours by IncuCyte. After 72 hours postwash, cell number was compiled over time as red cell count/mm ${ }^{2}$ and normalized to the initial cell count. Fraction of control growth, labeled cell survival, was then calculated as the measure of cytotoxicity. Cytotoxicity assays were performed in biologic triplicate, with each replicate in technical triplicate, for each microsome source used.

Kinetic Modeling of 4OHCP Exposure. The formation of $4 \mathrm{OHCP}$ and loss of $\mathrm{CP}$ were simulated in silico using MATLAB. Equations to describe $4 \mathrm{OHCP}$ formation (Michaelis-Menten equation) and CP loss (negative Michaelis-Menten equation) over time were designed as a system of ordinary differential equations (ODEs) and, when solved, represent a numerical solution to integrating the Michaelis-Menten equation. The empirically estimated kinetic parameters $\left(K_{\mathrm{M}}\right.$, $V_{\max }$ ), microsomal protein concentration, and reaction volume were used as constants. A chosen initial CP concentration and a concentration of $0 \mu \mathrm{M} 4 \mathrm{OHCP}$ were used as initial conditions. The system of ODEs was solved throughout a specified time frame using the MATLAB "ode45" solver. Output of the kinetic simulation is molar quantities of $\mathrm{CP}$ and $4 \mathrm{OHCP}$. The accuracy of the simulation to model kinetic behavior was tested by simulating the discontinuous kinetics assays, described earlier in the Materials and Methods, and re-estimating the kinetics parameters (Supplemental Table 1). This model assumes max kinetic efficiency and ignores off-target metabolism.

Cytotoxicity assays were simulated using the described model with each microsome used in vitro (H1, D4, C2, and M3). Concentration of $4 \mathrm{OHCP}$ versus time for each cytotoxicity assay was calculated by simulating reaction conditions, and exposure was calculated as the area under the curve (AUC) of predicted (4OHCP) versus time using the trapezoidal method and then correlated to cell survival/fraction of control growth. We chose to use AUC because it captures more information about the time-dependent exposure to 4OHCP, an intermediate in the CP biotransformation pathway (Fig. 1), than a single timepoint concentration.

PK Study in Mice. Mouse model protocols were approved by the Institutional Animal Care and Use Committee at Colorado State University. Female National Institutes of Health CD-1 Swiss mice, 21 total mice at three mice per time point, were treated with $100 \mathrm{mg} / \mathrm{kg}$ i.v. cyclophosphamide prepared in $0.9 \%$ veterinary grade saline. Whole blood was harvested throughout a time range of $0.08-4$ hours and was transferred to tubes containing sodium heparin. Blood was spun at $1200 \mathrm{~g}$ for 10 minutes at $4^{\circ} \mathrm{C}$. Subsequently, $100 \mu \mathrm{l}$ of plasma was transferred to a separate tube containing $10 \mu 12 \mathrm{M} \mathrm{SCZ}$, vortex-mixed, and frozen at $-80^{\circ} \mathrm{C}$. Plasma CP and 4OHCP were quantified via LC-MS/MS.

Western Blots and Densitometry Calculations. Microsomal CYP2B protein expression was visualized by Western blot. Microsomes were prepared in loading buffer (32.9 mM Tris- $\mathrm{HCl} \mathrm{pH} 6.8,13.2 \%$ glycerol, $1.1 \%$ SDS, and $0.005 \%$ bromophenol blue) and boiled at $95^{\circ} \mathrm{C}$ for 5 minutes. Fifteen micrograms of microsomal protein from each species was loaded per well, and proteins were separated via SDS-PAGE using an $8 \%-16 \%$ Tris-HCl Mini-PROTEAN TGX stain-free precast gel (Bio-Rad Laboratories, Hercules CA). Proteins were transferred to a PVDF membrane using the Trans-Blot Turbo transfer system (Bio-Rad Laboratories). Transfer was accomplished at 1.3A for 7 minutes. The membrane was blocked in 5\% skim milk prepared in Tris-buffered saline $+0.2 \%$ Tween 20 (TBS-T) for 1 hour at room temperature, incubated with primary antibody (diluted 1:1000) overnight in $5 \%$ milk at $4{ }^{\circ} \mathrm{C}$, washed three times with TBS-T, and incubated with secondary antibody (0031430, 1:10,000; ThermoFisher Scientific, Rockford, IL) in $1 \%$ milk for 2 hours at room temperature. The antibody used to probe for CYP2B (MA5-25882, clone OTI3D5; ThermoFisher Scientific) is a monoclonal antibody targeting human CYP2B6 and has known cross-species reactivity against dogs and mice. No cross-species reactivity against cats has been reported but is anticipated considering sequence homology between the orthologs (Supplemental Table 3). Blots were developed by chemiluminesence using the Clarity Western ECL substrate (Bio-Rad Laboratories), and total protein was determined using the stain-free feature of the Bio-Rad ChemiDoc MP system. Relative density of detected protein was calculated by dividing the pixel intensity of the chemiluminescent protein band by the pixel intensity of total lane protein using Fiji software (ImageJ, Bethesda, MD) (Schindelin et al., 2012; Schneider et al., 2012). Three independent Western blots were developed and an average relative density and standard deviation was then calculated for each microsome source.

Semiphysiologic Modeling of CP Pharmacokinetics. To investigate the accuracy of microsomal metabolism of $\mathrm{CP}$ for each species in vivo, the observed $K_{\mathrm{M}}$ and $V_{\max }$ values were applied to a semiphysiologic PK model. The model consisted of three flow-limited compartments representative of whole blood, liver, and the remainder of the body (Fig. 2). Physiologic tissue mass and blood flow were applied for each species as described for mice, dogs, and humans (Brown et al., 1997) and for cats (unpublished data, allometric scaling) as presented in Table 2 . To capture more fully the effect of metabolism on CP PK, the model was simplistically designed. Assumptions include intravenous dosing (bolus or infusion, depending on the clinical data used); equal tissue-to-plasma partitioning; clearance only in the hepatic space based on observed $K_{\mathrm{M}}, V_{\max }$, and cited microsomal protein per gram of liver $\left(P_{\text {mic }}\right)$ for each species as presented in Table 2. Protein binding was incorporated in the human model at roughly $50 \%$ fraction unbound (Bagley et al., 1973), where CP exhibits a low extraction ratio in the liver. In nonhuman species, CP exhibits a high extraction ratio in the liver; so the models were insensitive to changes in protein binding. For nonhuman species, protein binding was not included, which is physiologically representative of drug dissociation within the hepatic space for high extraction drugs (Meijer and van der Sluijs, 1989). Parameters included in the model were used as the cited value in literature and were not optimized for the simulation. Simulation output was compared against clinically obtained CP PK data for each species at the appropriate dose.

Scaling of the microsomal $V_{\max }$ to represent liver $V_{\max }$ in vivo was described by eq. 1. Equations for the rest of the body, liver, and plasma are represented by eqs. 2-4, respectively:

$$
\begin{aligned}
V_{\text {max }}^{l i v} & =V_{m a x}^{m i c} \cdot P_{m i c} \cdot V_{l i v} \\
\frac{d m_{r b}}{d t} & =Q_{r b} \cdot\left(C_{a}-C_{v, r b}\right) \\
\frac{d m_{l i v}}{d t} & =Q_{l i v} \cdot\left(C_{a}-C_{v, l i v}\right)-\left(\frac{C_{l i v} \cdot V_{m a x}^{l i v}}{K_{m} \cdot C_{l i v}}\right) \\
\frac{d m_{p l}}{d t} & =Q_{l i v} \cdot\left(C_{v, l i v}-C_{a}\right)-Q_{r b} \cdot\left(C_{v, r b}-C_{a}\right),
\end{aligned}
$$

where $m_{x}$ is the amount of $\mathrm{CP}$ within the compartment, $C_{a}$ is the arterial plasma concentration of $\mathrm{CP}, C_{v, x}$ is the venous plasma concentration of $\mathrm{CP}$ leaving each tissue where $x$ can represent liv (liver) or $r b$ (rest of body), $P_{\text {mic }}$ is the microsomal protein per gram of liver, $C_{l i v}$ is the total concentration of CP in the liver, $V_{l i v}$ is the volume of the liver, $Q_{x}$ is the blood flow rate to each tissue, and $K_{m}$ and $V_{\max }$ are Michaelis-Menten rate constants obtained in this study.

Computer Simulation and Software. The kinetics simulation model and semiphysiologic PK model were implemented in MATLAB version R2018a from 


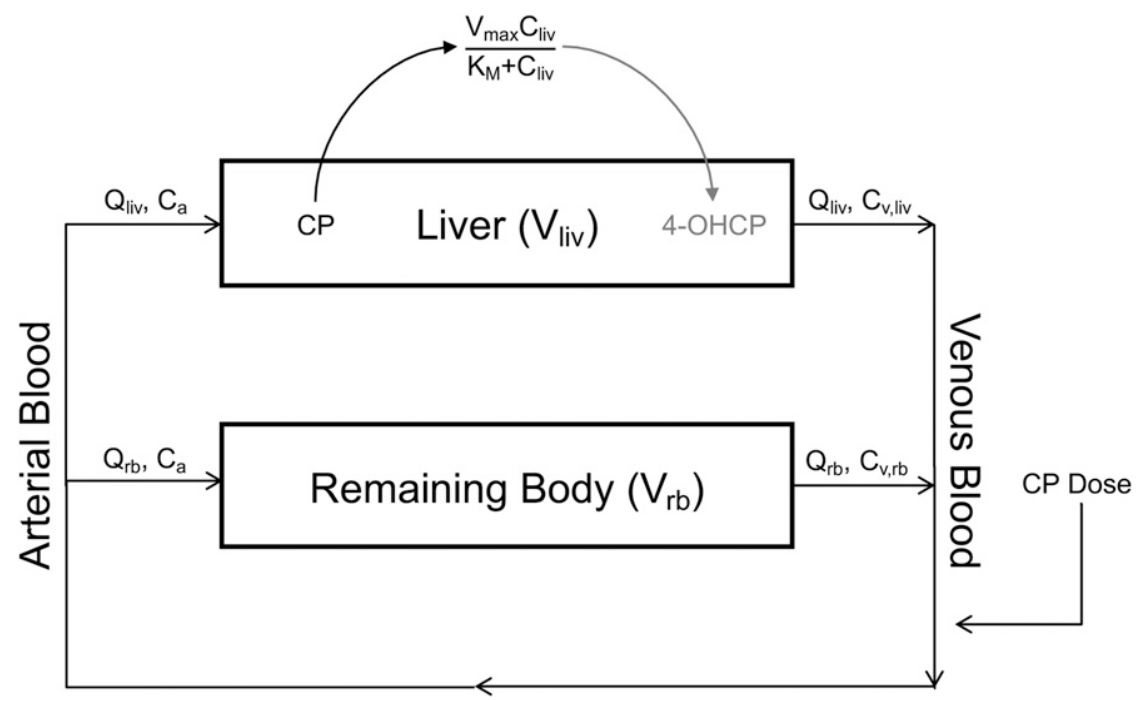

Fig. 2. Diagram of the semiphysiologic model used to simulate CP pharmacokinetics in vivo. CP delivery was modeled as intravenous bolus or infusion, depending on the study being simulated. Distribution from the plasma to the liver and remaining body was modeled based on speciesspecific cardiac output and fraction of that cardiac output delivered to the tissue. The single route of elimination for $\mathrm{CP}$ was modeled as metabolism into $4 \mathrm{OHCP}$ occurring only in the liver based on the Michaelis-Menten parameters observed for each species. In vitro microsome $K_{\mathrm{m}}$ and $V_{\max }$ values were scaled by reported liver volume and microsomal protein per gram of liver for each species, referenced in eq. 1 and Table 2.

The MathWorks, Inc. (Natick, MA). Clinical and simulated pharmacokinetic metrics were calculated via noncompartmental analysis on Phoenix 64 WinNonlin build 8.0.0.3176, Certara LP (St. Louis, MO).

\section{Results}

Species-Dependent Differential Kinetics of 4OHCP Formation in Microsomes. Microsomes from humans, dogs, cats, and mice were used to determine the kinetics of $4 \mathrm{OHCP}$ formation (Fig. 3). Microsome source information, including species identification used throughout the rest of this article $(\mathrm{H}=$ human, $\mathrm{D}=\mathrm{dog}, \mathrm{C}=$ cat, $\mathrm{M}=$ mouse $)$ is included in Table 1. 4OHCP formation was determined to be linear at the times described in the Materials and Methods, satisfying the steady-state assumption (data not shown). Curves were fit, and kinetic parameters were estimated under the assumption of a Michaelis-Menten oneenzyme model (Table 3). Curves for microsomes D1 and C2 were performed at $\mathrm{CP}$ concentrations dissimilar to the other microsomes because they were the first to be tested, and we had no remaining microsomes from these sources to redo the assays at the ranges shown for the rest of the microsomes. No data points were left out of any curve for the kinetics analysis (see Materials and Methods). Comparison of $V_{\max } / K_{\mathrm{M}}$, presented here as intrinsic clearance $\left(C L_{\text {int }}\right)$, suggests a metabolic stratification between the different species. Dog microsomes were, on average, 55-fold more efficient than human microsomes, 2.8-fold more efficient than cat microsomes and 1.2-fold more efficient than mouse microsomes at catalyzing $\mathrm{CP}$ bioactivation.

The assumption of the one-enzyme model was evaluated by transforming the Michaelis-Menten plots in Fig. 3 according to the EadieHofstee linearization (Supplemental Fig. 1). For all Eadie-Hofstee data, we compared the fit of a line versus exponential decay and selected the best of the two using Akaike Information Criterion corrected for small sample size implemented in GraphPad Prism 7.0d. Despite no evidence of atypical kinetic behavior in the Michaelis-Menten plots, linearization and subsequent fit comparisons revealed that M1, M2, and M3 kinetics behave in a biphasic fashion (Supplemental Fig. 1A). Kinetics data for microsome $\mathrm{C} 1$ visually can resemble either an exponential decay or a line; indeed, model comparison selected exponential decay to describe $\mathrm{C} 1$ but with remarkably less confidence compared with the model selections for M1, M2, or M3 (data not shown). Thus, C1 kinetic behavior was regarded as monophasic in agreement with the assumptions made in the preceding. The biphasic behavior for M1, M2, and M3 was separated into a "fast" and "slow" set of kinetic parameters, defined as low-affinity/high-turnover and high-affinity/low-turnover, respectively. These parameters are presented in Supplemental Fig. 1B. Notably, the fast kinetic parameters for each microsome are similar to the monophasic parameters estimated from nonlinear regression.

TABLE 2

Physiologic parameters used to construct semiphysiologic model

\begin{tabular}{|c|c|c|c|c|c|}
\hline & & Human & Dog & Cat & Mouse \\
\hline \multirow{5}{*}{ Fraction of bodyweight } & Bodyweight $(\mathrm{kg})^{a}$ & 70 & 25 & 4 & 0.02 \\
\hline & Blood $^{a}$ & 0.079 & 0.082 & 0.08 & 0.049 \\
\hline & Liver $^{a}$ & 0.0257 & 0.0329 & 0.0329 & 0.055 \\
\hline & Remaining & 0.8953 & 0.8851 & 0.8871 & 0.896 \\
\hline & Cardiac output $(\mathrm{ml} / \mathrm{min})^{b}$ & $\begin{array}{l}6.66 \times \\
10^{3}\end{array}$ & $\begin{array}{c}3.07 \times \\
10^{3}\end{array}$ & 777.8175 & 14.6253 \\
\hline \multirow{3}{*}{$\begin{array}{l}\text { Fraction of cardiac } \\
\text { output }\end{array}$} & Liver $^{a}$ & 0.227 & 0.297 & 0.202 & 0.161 \\
\hline & Remaining & 0.773 & 0.703 & 0.798 & 0.839 \\
\hline & $\begin{array}{l}\text { Microsomal protein (mg protein/g of } \\
\text { liver) }\end{array}$ & $50^{c}$ & $55^{d}$ & $48^{e}$ & $87^{f}$ \\
\hline
\end{tabular}

${ }^{a}$ Brown et al. (1997).

${ }^{b}$ Cardiac output parameter calculated by allometric scaling.

${ }^{c}$ Carlile et al. (1999), Barter et al. (2007).

${ }^{d}$ Smith et al. (2008).

${ }^{e}$ Visser et al. (2018).

${ }^{f}$ Gibhard et al. (2016) 
A

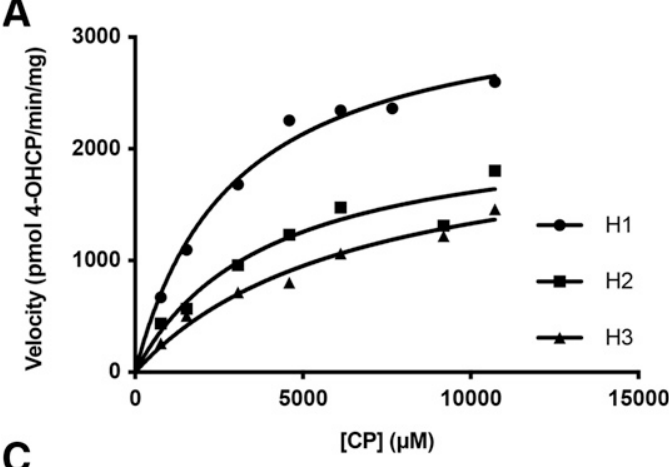

C

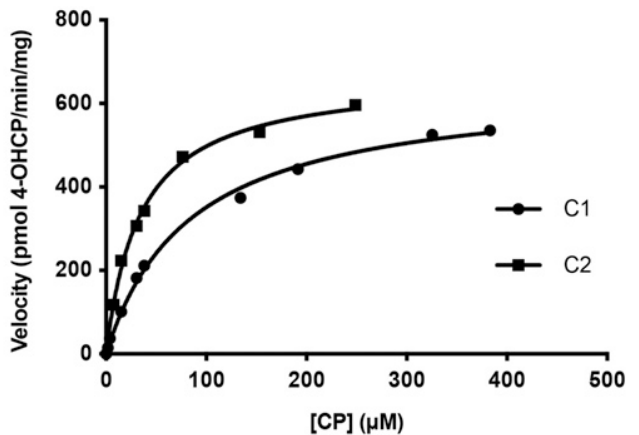

B

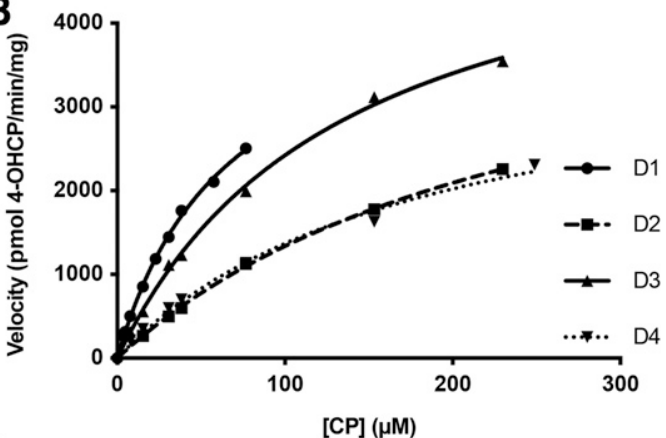

D

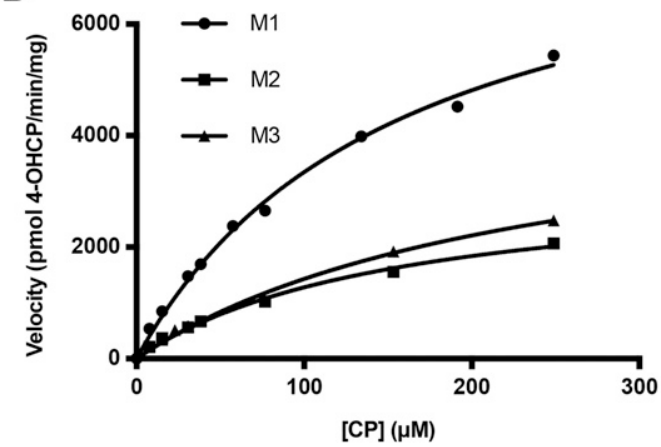

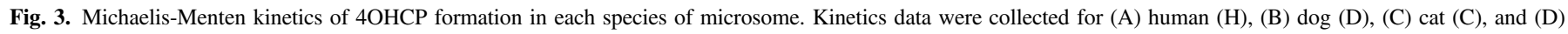

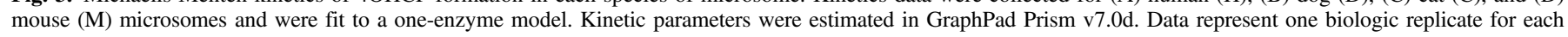
microsome source.

We designed a kinetic simulation model in MATLAB that simulates concentration- versus-time curves for the metabolic conversion of $\mathrm{CP}$ to 4OHCP, as described in the Materials and Methods. This model was tested using each set of microsomal kinetic parameters by simulating the discontinuous kinetics assay and re-estimating the kinetics parameters to verify the accuracy of the simulation model (shown in Supplemental Fig. 2). Supplemental Table 1 contains the comparison of empirical to simulated kinetics parameters for each microsomal source. In all cases, the simulation model overpredicts the kinetics parameters but, on average, by no more than $2.4 \%$ of empirical. This finding demonstrates that the observed microsomal kinetics can be adequately modeled by monophasic kinetics within reasonable error.

Microsomal Kinetics Predict In Vitro Cell Death. We sought to investigate more fully the in vitro differential $4 \mathrm{OHCP}$ formation kinetics as a precursor to evaluating clinical data. As a first measure of understanding in vitro metabolic differences, the conversion of $\mathrm{CP}$ to $4 \mathrm{OHCP}$ was monitored using the XenoTech-derived microsomes in $0.1 \mathrm{M}$ phosphate buffer. Using a constant $\mathrm{CP}$ concentration $(7.6 \mu \mathrm{M})$, time point (30 minutes), and protein concentration $(0.5 \mathrm{mg} / \mathrm{ml})$ for each microsome (H1, D4, C2, M3), the percentage of CP metabolized into 4OHCP was determined to be $2.59 \%$ for $\mathrm{H} 1,39.23 \%$ for $\mathrm{D} 4,19.06 \%$ for $\mathrm{C} 1$, and $23.23 \%$ for $\mathrm{M} 3$ from one experiment. Additionally, theoretical 4OHCP formation was estimated from the loss of $\mathrm{CP}$ under the assumption of $100 \%$ conversion to measurable $4 \mathrm{OHCP}$ (from the same preceding experiment); for each microsome, the ratio of measurable to theoretical $4 \mathrm{OHCP}$ is 0.3408 for $\mathrm{H} 1,0.7846$ for $\mathrm{D} 4,0.8311$ for $\mathrm{C} 2$, and 0.8630 for M3. These data demonstrate that the primary metabolite formed in vitro is $4 \mathrm{OHCP}$ for only the nonhuman microsomes. Furthermore, this implies that in vitro manifestations of metabolic differences should also be apparent in cellular-based systems.

TABLE 3

Michaelis-Menten kinetics parameters and clearance estimates for each source of microsomes

The data are listed as the parameter estimate \pm S.E. of the curve fit ${ }^{\mathrm{a}}$ and are based on $\mathrm{n}=1$ biologic replicate.

\begin{tabular}{|c|c|c|c|c|}
\hline Species & ID & $V_{\max }(\mathrm{pmol} 4 \mathrm{OHCP} / \mathrm{min}$ per $\mathrm{mg})$ & $K_{\mathrm{M}}(\mu \mathrm{M})$ & $C L_{\text {int }}\left(V_{\max } / K_{\mathrm{M}}\right)\left(\mu \mathrm{l} / \mathrm{min}^{-1} * \mathrm{mg}^{-1}\right)$ \\
\hline \multirow[t]{3}{*}{ Human } & $\mathrm{H} 1$ & $3372 \pm 193.8$ & $2908 \pm 463.5$ & 1.160 \\
\hline & $\mathrm{H} 2$ & $2238 \pm 333.8$ & $3906 \pm 1453$ & 0.5730 \\
\hline & $\mathrm{H} 3$ & $2214 \pm 310.5$ & $6631 \pm 1865$ & 0.3339 \\
\hline \multirow[t]{4}{*}{ Dog } & D1 & $4633 \pm 173.3$ & $66.08 \pm 4.186$ & 70.11 \\
\hline & $\mathrm{D} 2$ & $4803 \pm 159.9$ & $259.1 \pm 13.38$ & 18.54 \\
\hline & D3 & $5707 \pm 236.5$ & $135.6 \pm 11.07$ & 42.09 \\
\hline & D4 & $3862 \pm 393.1$ & $182.0 \pm 33.79$ & 21.22 \\
\hline \multirow[t]{2}{*}{ Cat } & $\mathrm{C} 1$ & $646.7 \pm 15.68$ & $84.09 \pm 6.223$ & 7.691 \\
\hline & $\mathrm{C} 2$ & $668.0 \pm 16.00$ & $34.33 \pm 2.518$ & 19.46 \\
\hline \multirow[t]{3}{*}{ Mouse } & M1 & $8577 \pm 468.7$ & $156.4 \pm 16.23$ & 54.84 \\
\hline & M2 & $3278 \pm 260.4$ & $156.3 \pm 23.79$ & 20.97 \\
\hline & M3 & $4859 \pm 485.4$ & $239.9 \pm 39.69$ & 20.25 \\
\hline
\end{tabular}

${ }^{a}$ Goodness-of-fit from nonlinear regression for each collection of microsomes is as follows: human, $R_{\text {adj }}^{2}>0.90 ;$ dog, $R_{\text {adj }}^{2}>0.98$; cat, $R_{\text {adj }}^{2}>0.99$; and mouse, $R_{\text {adj }}^{2}>0.99$. 
To that end, we designed a cytotoxicity assay that mimics $4 \mathrm{OHCP}$ drug exposure to MDA-MB-231 human breast cancer cells, selected because triple-negative breast cancers, from which MDA-MB-231 is derived, are commonly treated with cyclophosphamide and thus is a clinically representative in vitro model to study $\mathrm{CP}$ cytotoxicity. We first determined the effect of Ham's F12 media-which is used for maintaining MDA-MB-231 cells-on microsome catalytic activity by re-estimating the kinetic parameters in microsomes from Sekisui XenoTech, LLC (Kansas City, KS) (H1, D4, C2, and M3). These microsomes were selected because of microsome quantity constraints. The kinetic parameters for each XenoTech microsome source in Ham's F12 media are as follows $\left[V_{\max } \pm\right.$ S.E. (pmol 4-OHCP/min per milligram-protein), $K_{M} \pm$ S.E. $\left.(\mu M)\right]: \mathrm{H} 1[3793 \pm 325.1,1885 \pm$ 553.4], D4 [4733 $\pm 381.3,83.10 \pm 15.47]$, C2 [752.8 \pm 40.64, 50.98 $\pm 7.413]$, and M3 [9425 $\pm 461.5,93.02 \pm 10.15]$. The $V_{\max }$ estimated in Ham's F12 media increased relative to parameters estimated in $0.1 \mathrm{M}$ phosphate buffer, and the $K_{\mathrm{M}}$ decreased for all but $\mathrm{C} 2$. Intrinsic clearances $\left(V_{\max } / K_{\mathrm{M}}\right)$ compared between the two media conditions are shown in Supplemental Table 2 and demonstrate that H1, D4, and M3 microsomes become more catalytically active in Ham's F12 media relative to phosphate buffer. The calculated intrinsic clearance of $\mathrm{C} 2$ microsomes in Ham's F12 relative to phosphate buffer decreased by 0.7590 -fold. The kinetic profiles from Ham's F12 media were EadieHofstee transformed, according to the workflow described in the Materials and Methods, and none of the kinetics displayed biphasic kinetics (data not shown), in contrast to the behavior observed for M3 in phosphate buffer.

For the cytotoxicity assay, we treated cells with microsomes and $\mathrm{CP}$ at a range from 3.8 to $3831 \mu \mathrm{M}$ for 2 hours, then monitored cytotoxicity and quantified cell death after 72 hours via IncuCyte imaging. These concentrations were chosen to encompass a wide range of pharmacologic CP concentrations observed at clinically relevant doses, which includes the following: cat $C_{\max }=35.2 \mu \mathrm{M}$ (Stroda et al., 2017), dog
$C_{\max }=78.5 \mu \mathrm{M}$ (Warry et al., 2011), mouse $C_{\max }=204.1 \mu \mathrm{M}$, and human $C_{\max }=700 \mu \mathrm{M}$ (Chen et al., 1995). Nonpharmacologic concentrations of $\mathrm{CP}$ were also included to capture fully the cytotoxic phenomena. We observed cytotoxicity profiles that resemble traditional dose-response curves (Fig. 4A). Cell survival was normalized as the fraction of control for each microsome condition so that comparisons could be made across each species. Cells treated with either dog or mouse microsomes demonstrated the greatest response relative to cat microsomes, which produced an intermediate sensitivity phenotype, and human microsomes, which demonstrated the least sensitivity. The $\mathrm{IC}_{50}$ estimates for each curve are H1, $1857 \mu \mathrm{M}$; D4, $31.65 \mu \mathrm{M}$; C2, $272.6 \mu \mathrm{M}$; and M3, $44.95 \mu \mathrm{M}$.

The cytotoxicity curves only consider the initial CP concentration as it relates to cell death; exposure of $4 \mathrm{OHCP}$ is the most important measure as $4 \mathrm{OHCP}$ directly transforms to the cytotoxic agent, PM. To understand the relationship between $4 \mathrm{OHCP}$ exposure and cell death, we used the kinetic simulation model described previously in the text. 4OHCP concentration was simulated for each cytotoxicity experiment using this simulation model, and the resultant exposure was predicted and related to cell death (Fig. 4B). Correlations between cell death and predicted 4OHCP exposure were calculated for human (Spearman $\rho=-0.6$, $P=0.0968), \operatorname{dog}($ Spearman $\rho=-1$; *** $P<0.001)$, cat (Spearman $\rho=-0.9333$, $* * * P<0.001$ ), and mouse (Spearman $\rho=-0.9643$, $* * P<0.01)$ microsomes. The Spearman correlation between overall cell death and predicted exposure, without separating the data by species, was significant (Spearman $\rho=-0.8691 ; 95 \%$ CI: $-0.9359,-0.7420$; $* * * * P<0.0001)$. This model makes two assumptions: 1) $100 \%$ of produced $4 \mathrm{OHCP}$ is converted to $\mathrm{PM}$ and available for alkylation; and 2) activation of off-target metabolic pathways throughout the assay is negligible.

Since CYP2B6 is hypothesized to be the critical metabolizing enzyme for CP bioactivation (see Introduction), we sought to characterize the in vitro expression of CYP2B orthologs in these microsomes. We
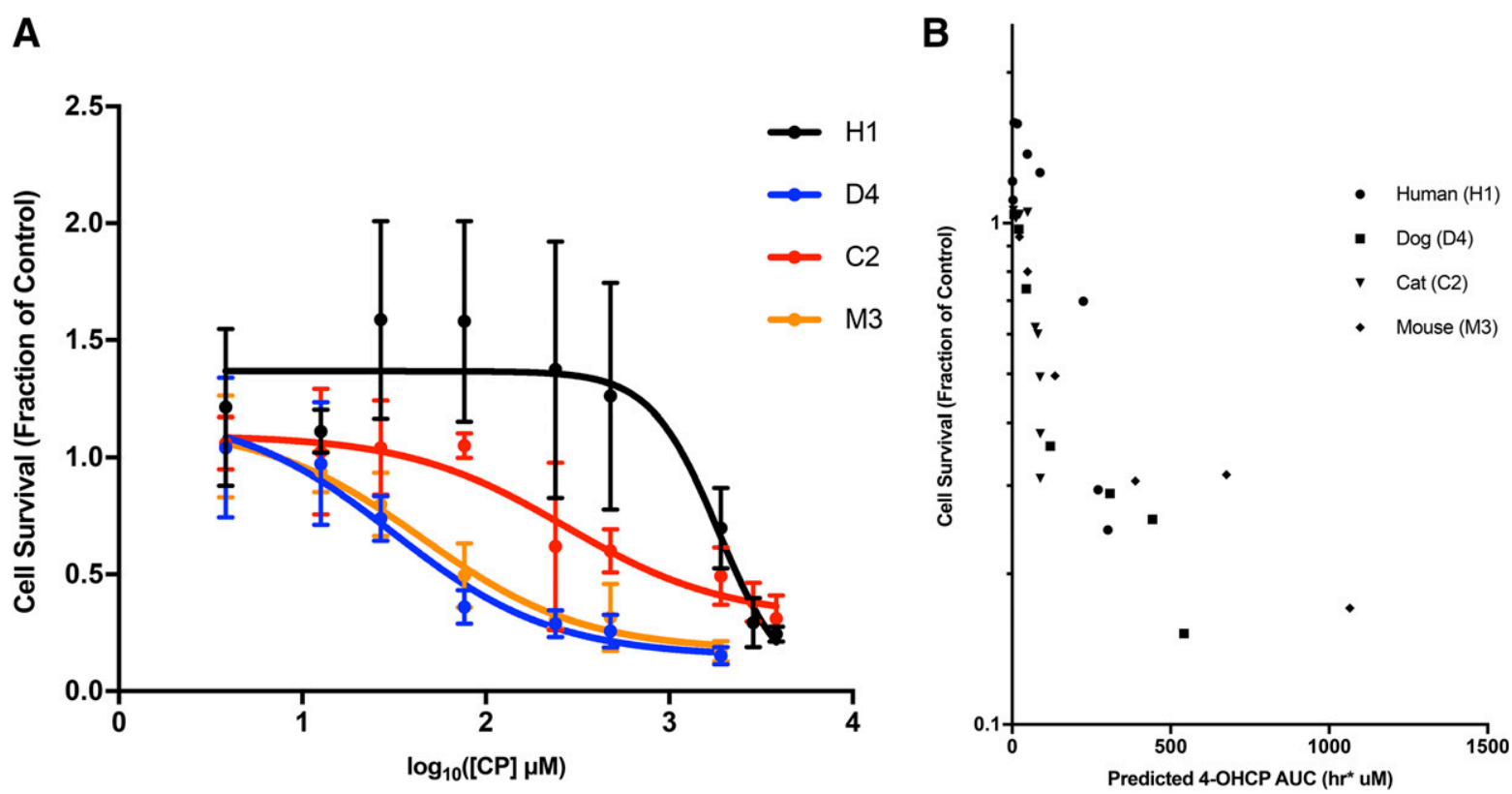

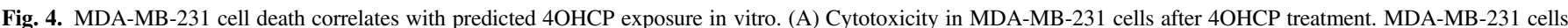

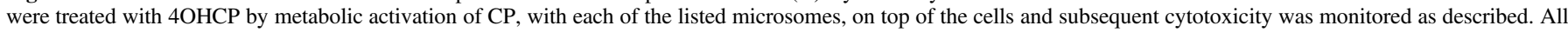

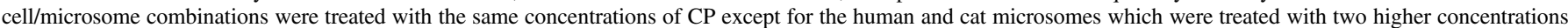

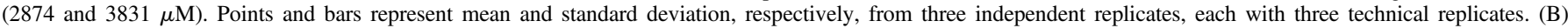

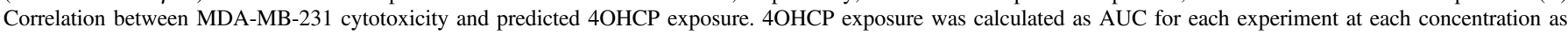

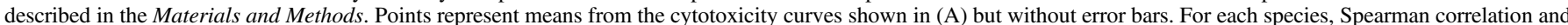
two-tailed $P$ value were calculated with GraphPad Prism v7.0d. 
compared orthologous CYP2B sequences between the four studied species, based on published canonical sequences, and found a high degree of homology between each sequence (Supplemental Table 3). The lowest percentage of homology was observed between cat and mouse orthologs at $84.2 \%$, whereas the highest percentage of homology was observed between cat and dog orthologs at $91 \%$.

The CYP2B expression status for available microsomes was determined via Western blot (Fig. 5A), and consistent protein loading was confirmed by total protein scan (Supplemental Fig. 3). Densitometry was used to determine the relative density of each chemilumiescent CYP2B protein band against the total protein (Supplemental Table 4). Mouse microsomes expressed the most CYP2B: 3.1-fold more than dogs, 7.5-fold more than humans, and 203-fold more than cats, on average. The virtually undetectable CYP2B ortholog in C2 cat microsomes is notable. Means (without S.D.) of densitometry calculations from three independent western blots probing CYP2B (Supplemental Table 4) were plotted (along the abscissa) against microsomal $\mathrm{V}_{\max }$; there exists a statistically significant Spearman correlation between these two variables (Spearman $\rho=0.8333$; ${ }^{*} P<0.05$ ) (Fig. 5B).

In addition to $\mathrm{CYP} 2 \mathrm{~B}$, we sought to understand the contribution of CYP2C9/2C19 and CYP3A4 orthologs in CP bioactivation for each of the species. Antibodies targeting these orthologs are not readily available for cross-reactivity against our species panel, so we used chemical inhibitors to ablate CYP activity in each of the XenoTech (H1, D4, $\mathrm{C} 2$, and M3) microsomes and observed the effect on CP bioactivation. Microsomal 4OHCP formation was measured in the presence of each P450 inhibitor (Fig. 5C). 4OHCP formation is presented as the AUC from the $4 \mathrm{OHCP}$ concentration versus time curve for each condition normalized to the CP control condition (see Materials and Methods). Ketoconazole, an inhibitor of CYP3A4, has no apparent impact on 4OHCP formation in any of the microsomes. This is similarly true for miconazole, inhibitor of CYP2C19 and CYP3A4, although a slight enzyme impedance is observed in the dog and human microsomes. CBP, an inhibitor of CYP2B6, has relatively little influence on $4 \mathrm{OHCP}$ formation except in cat microsomes, where it significantly reduces enzyme activity (ratio of $\mathrm{AUC}_{+\mathrm{CP}, \mathrm{CBP}} / \mathrm{AUC}_{+\mathrm{CP}}$ $=0.227$ ). Fluconazole, an inhibitor of CYP2C9 and CYP3A4, inhibits 4OHCP formation to the greatest extent and affects all four of the tested species. Most notable is the effect of fluconazole in dog microsomes, which results in nearly complete ablation of 4OHCP formation (ratio of $\mathrm{AUC}_{+\mathrm{CP}}$, fluconazole $/ \mathrm{AUC}_{+\mathrm{CP}}=0.0148$ ). Two additional inhibitors specific to canine $\mathrm{P} 450$ s were tested in dog microsomes only. Sulfaphenazole, an inhibitor of canine CYP2C21/ 41 , reduces $4 \mathrm{OHCP}$ formation by nearly half compared with control, and chloramphenicol, an inhibitor of CYP2B11, does not inhibit 4OHCP formation.
A

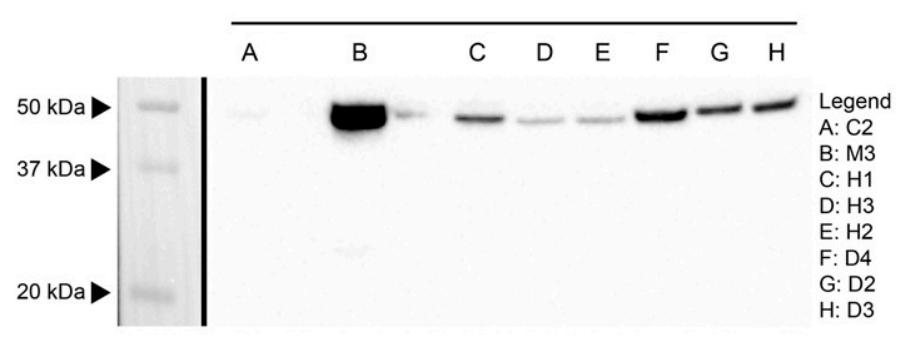

C

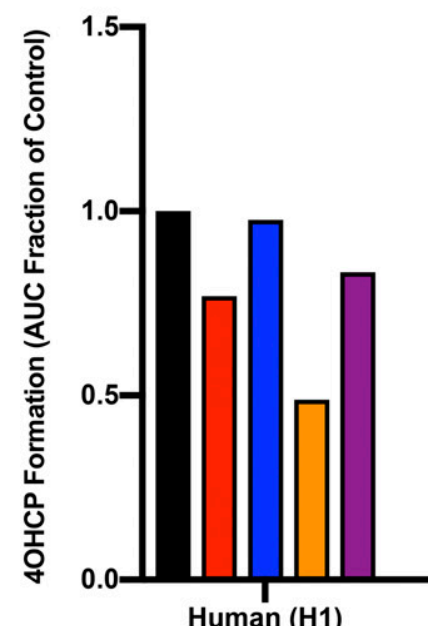

Human (H1)
IB: CYP2B

B

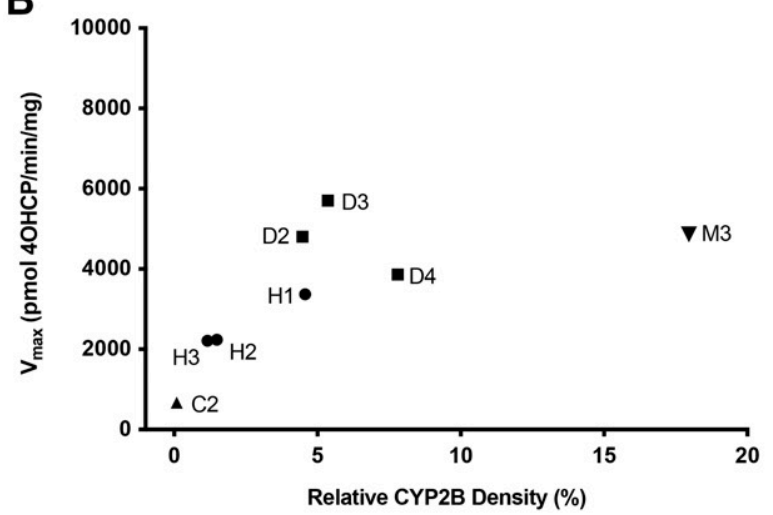

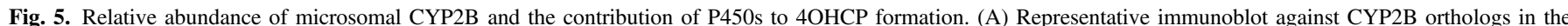

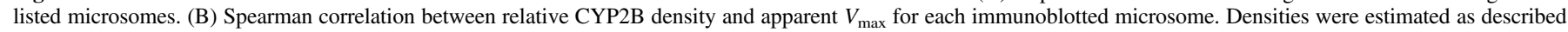

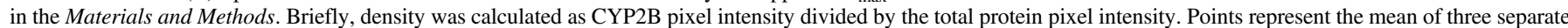

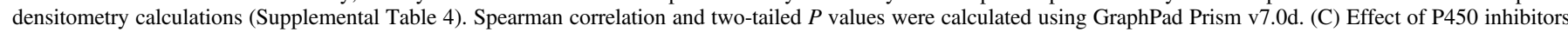

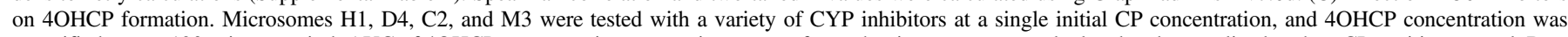

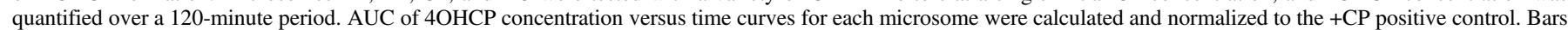
represent normalized AUC of one time-course experiment for each condition. 
Microsomal 4OHCP Formation Kinetics Influences CP Pharmacokinetics. To understand more completely the influence of in vitro metabolism on CP PK and assess the in vivo accuracy of the observed 4OHCP formation kinetics, microsomal kinetics parameters were incorporated into a three-compartment semiphysiologic PK model and compared against clinically obtained PK data. PK data from mice were generated after a single i.v. dose of $\mathrm{CP}$ at $100 \mathrm{mg} / \mathrm{kg}$. Whole blood and organs were harvested at $0.08,0.25,0.5,1.0,2.0,3.0$, and 4.0 hours after dosing. CP concentrations in plasma were used (Supplemental Fig. 4). Plasma PK data from canine (Warry et al., 2011), feline (Stroda et al., 2017), and human (Struck et al., 1987; Chen et al., 1995) subjects were also used in the model. Simulated PK data from the model were compared against the intravenous dosing scheme (bolus or infusion) and clinical PK data. The model closely simulated the mean plasma CP concentrations of each animal species, as depicted in Fig. 6 (animal graphs), and two human studies in Fig. 7 (graphs on humans).

The ability of the model to predict CP PK accurately was determined by comparing parameters derived from noncompartmental analysis (Table 4). AUC and half-life $\left(t_{1 / 2}\right)$ for clinical and simulated data were compared ratiometrically. Dog, cat, and mouse comparisons result in respective AUC simulated/actual ratios of 1.07, 1.39, 2.35, and $t_{1 / 2}$ of 1.09, 1.38, and 1.21 (Fig. 6). Model output using each species' scaled kinetic parameters incorporated into the semiphysiologic model was remarkably similar between each batch of microsomes, emphasizing the blood flow-limited nature of $\mathrm{CP}$ metabolism in these species. For both human PK studies, the model tended to underestimate the AUC, with simulated/actual ratios of 0.79 and 0.58 , and slightly overestimate the $t_{1 / 2}$, with simulated/actual ratios of 1.15 and 1.60. In both PK studies, H3 exhibited the best performance when applied to the semiphysiologic model.

\section{Discussion}

The need for better understanding of animal CP metabolism, within the context of veterinary research, warranted the current study. The data herein demonstrate the importance of in vitro metabolism on CP PK in species frequently treated with $\mathrm{CP}$ and the utility of post-hoc clinical modeling in coordination with preclinical data to understand important factors of PK. Physiologically based PK modeling largely serves this purpose, but the present study highlights the common paradigm in mathematical modeling that simple models can produce fruitful interpretations (Gunawardena, 2014).

The present study is not the first to investigate $\mathrm{CP}$ metabolism in humans; the kinetic parameters presented herein are similar to published data derived from liver metabolic data (Anderson et al., 1996), microsomes (Ren et al., 1997), and supersomes (Roy et al., 1999; Huang et al., 2000). Likewise, the presented dog parameters are comparable to other published studies (Chen et al., 2004; Lautier et al., 2016). Parameters for cat and mouse microsomes, in contrast, have not been published. The presentation of biphasic 4OHCP formation kinetics from microsomal systems (i.e., in the studied mouse sources), although interesting, is not sufficient to demonstrate the nature of the kinetic mechanisms at play. Certain P450 enzymes are known to behave in ways that are not in full agreement with Michaelis-Menten kinetics, but when experiments are performed using multienzyme systems—-such as with liver microsomes - observed atypical kinetics may be artifactual instead of real (Hutzler and Tracy, 2002). For example, previous characterization of human liver microsomes were decidedly biphasic in regard to 4OHCP formation kinetics (Ren et al., 1997), yet data in the current study contradict that finding. It is unknown how much either of these data was influenced by artifactual biases. It is important to remember that P450s involved in xenobiotic metabolism are generally

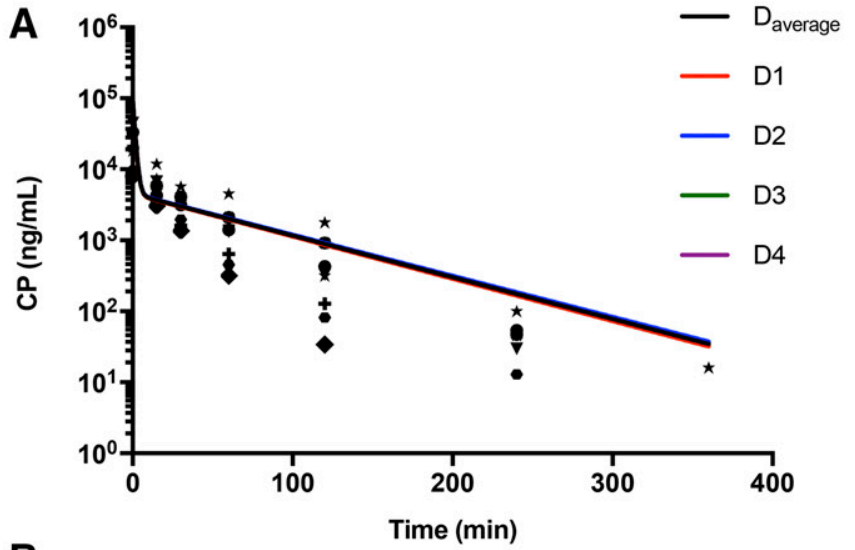

B
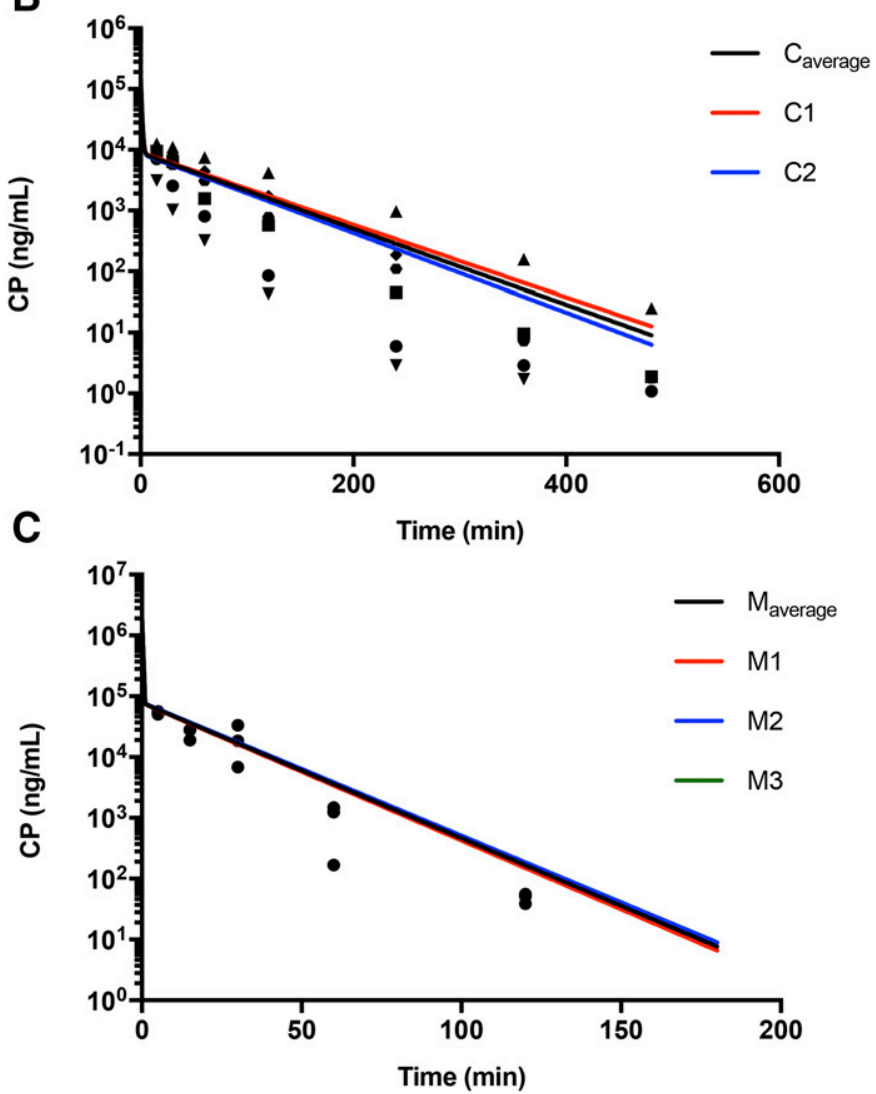

Fig. 6. Comparison of animal CP plasma PK data to simulated CP concentration using a semiphysiologic model. A semiphysiologic model describing the metabolism of CP was generated and used to simulate CP PK using each of the listed microsome's kinetics parameters. Simulation output, in colored lines, is compared with published PK data for (A) dogs (Warry et al., 2011), (B) cats (Stroda et al., 2017), and (C) mice (Supplemental Fig. 4), where each symbol represents plasma $\mathrm{CP}$ concentrations from one animal subject.

considered catalytically promiscuous because these enzymes can display broad specificity for substrates (Bernhardt, 2006). Thus, observing biphasic kinetics from microsomes might not be surprising considering what is currently known about P450 contributions to CP metabolism. Nevertheless, apparent monophasic kinetics obtained from microsomes are still useful and are important for many aspects of drug discovery (Vrbanac and Slauter, 2013). Indeed, when comparing kinetic parameters, particularly the microsomal intrinsic clearance among sources $\mathrm{H}$, D4, C2, and M3, the monophasic kinetics predict the differences in observed cytotoxicity profiles and calculated $\mathrm{IC}_{50}$ values. We did not observe significant correlation between cell survival and predicted 

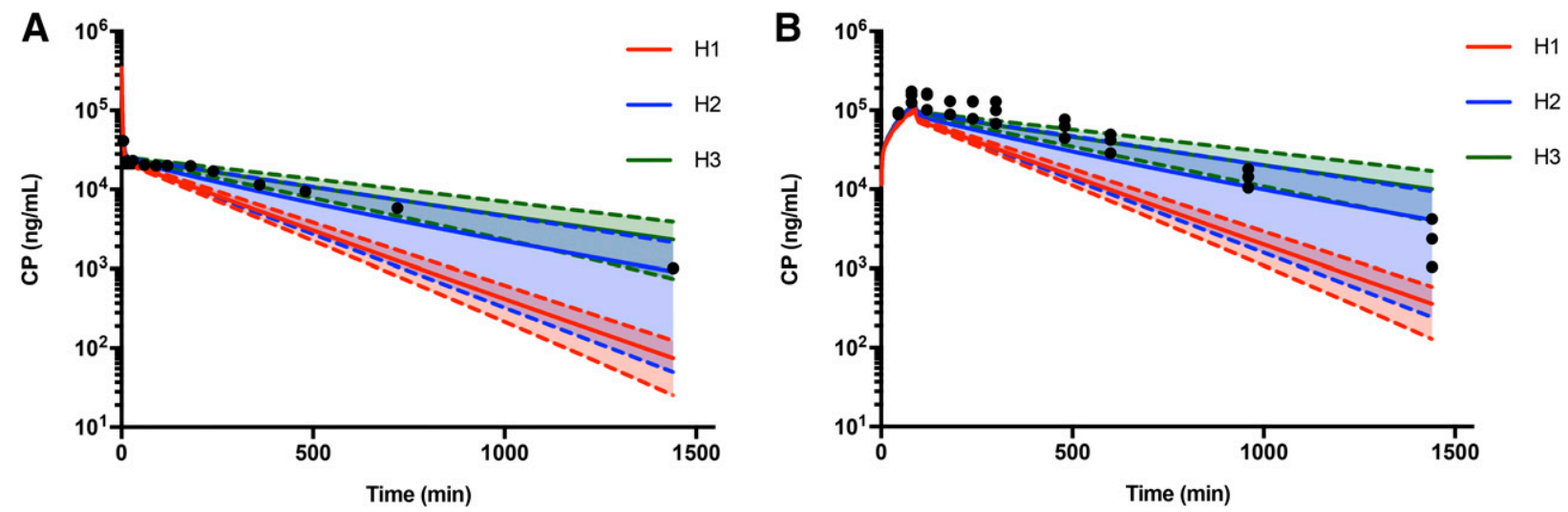

Fig. 7. Comparison of human CP plasma PK data to simulated CP concentration using a semiphysiologic model. A semiphysiologic model describing the human metabolism of CP was generated and used to simulate CP PK using the kinetics parameters from H1, H2, and H3. Model output is represented as the simulated mean (solid lines) \pm S.D. (filled area to dotted lines) compared with two sets of published CP PK data, (A) (Struck et al., 1987) and (B) (Chen et al., 1995), where each symbol represents plasma CP concentrations from one patient. Dosing was modeled as (A) intravenous bolus or (B) 90-minute intravenous infusion.

4OHCP exposure in human microsomes in contrast to the others, but we attribute this to the undetectable cell death at most $\mathrm{CP}$ concentrations tested and would expect to see a correlation if we extended the $\mathrm{CP}$ range well beyond the already nonpharmacologically relevant concentrations.

The importance of human CYP2B6 in CP metabolism has been studied extensively, and although several isozymes are believed to contribute to CP hydroxylation, CYP2B6 is frequently singled out as most significant (Xie et al., 2003; Rodriguez-Antona and IngelmanSundberg, 2006). The undetectable CYP2B ortholog in short-hair cats is unexpected, but a recent study has demonstrated that cats lack apparent liver expression of their CYP2B ortholog (Okamatsu et al., 2017). Some human liver microsomes derived from patients evidently lack CYP2B6 expression, but not to the same extent as cats (Xie et al., 2003). Humans are not known to express CYP2B6 anywhere but the liver (Thelen and Dressman, 2009). As for canines, beagles express CYP2B11, their
CYP2B6 ortholog (Heikkinen et al., 2012), but differential expression across breeds is undocumented, and its effect on overall CP metabolism has remained elusive. Although increasing age ( $\geq$ adult) has been thought to influence P450 expression, studies suggest that in humans and dogs, only P450 activity seems to be negatively impacted (Tibbitts, 2003; Zanger and Schwab, 2013).

As mentioned previously, several P450s have been implicated in the bioactivation of $\mathrm{CP}$. The data presented herein demonstrate that ketoconazole failed to inhibit $4 \mathrm{OHCP}$ formation, suggesting that CYP3A4 and its animal orthologs contribute very little to the formation of 4OHCP. Fluconazole, the CYP2C9 inhibitor, had the greatest impact on 4OHCP formation in humans compared with the CYP2B6 (CBP) and CYP2C19 (miconazole) inhibitor, although we conclude that both CYP2C9 and CYP2B6 are involved CP metabolism. This conclusion is applicable to mice, assuming fluconazole and $\mathrm{CBP}$ inhibit mouse

TABLE 4

Noncompartmental analysis comparisons between actual cyclophosphamide (CP) pharmacokinetic (PK) data versus semiphysiologic simulation predicted CP PK data

Data for area under the curve (AUC) and $\mathrm{t}_{1 / 2}$ are presented as mean and S.D. Units are as follows: AUC (mM $\left.\cdot \mathrm{h}\right) ; \mathrm{t}_{1 / 2}(\mathrm{~h}) ; \mathrm{dose}(\mathrm{mg} / \mathrm{kg})$.

\begin{tabular}{|c|c|c|c|c|c|c|c|c|c|}
\hline & & AUC (mean) & AUC (S.D.) & Ratio (sim/actual) & $\mathrm{t}_{1 / 2}($ mean $)$ & $\mathrm{t}_{1 / 2}$ (S.D.) & Ratio (sim/actual) & Dose (mean) & Dose (S.D.) \\
\hline Human & Actual & 48.84 & 2.17 & & 4.92 & 0.11 & & 27 & 0 \\
\hline \multirow{4}{*}{ Struck et al. (1987) } & Averaged & 38.42 & & 0.79 & 5.64 & & 1.15 & 27 & \\
\hline & 1 & 23.82 & & 0.49 & 2.84 & & 0.58 & 27 & \\
\hline & 2 & 37.47 & & 0.77 & 4.42 & & 0.90 & 27 & \\
\hline & 3 & 53.98 & & 1.11 & 6.67 & & 1.35 & 27 & \\
\hline Human & Actual & 261.53 & 47.41 & & 3.53 & 0.67 & & 108 & \\
\hline \multirow[t]{4}{*}{ Chen et al. (1995) } & Averaged & 152.58 & & 0.58 & 5.62 & & 1.60 & 108 & \\
\hline & 1 & 94.783 & & 0.36 & 2.84 & & 0.81 & 108 & \\
\hline & 2 & 148.48 & & 0.57 & 4.44 & & 1.26 & 108 & \\
\hline & 3 & 214.49 & & 0.82 & 6.70 & & 1.90 & 108 & \\
\hline \multirow[t]{6}{*}{ Dog } & Actual & 1.64 & 0.87 & & 0.78 & 0.38 & & 11.8 & 1.46 \\
\hline & Averaged & 1.75 & & 1.07 & 0.85 & & 1.09 & 12 & \\
\hline & 1 & 1.72 & & 1.05 & 0.84 & & 1.08 & 12 & \\
\hline & 2 & 1.78 & & 1.09 & 0.87 & & 1.11 & 12 & \\
\hline & 3 & 1.73 & & 1.06 & 0.85 & & 1.08 & 12 & \\
\hline & 4 & 1.77 & & 1.08 & 0.86 & & 1.10 & 12 & \\
\hline \multirow[t]{4}{*}{ Cat } & Actual & 2.06 & 1.76 & & 0.59 & 0.24 & & 8.02 & 1 \\
\hline & Averaged & 2.87 & & 1.39 & 0.80 & & 1.38 & 8 & \\
\hline & 1 & 3.03 & & 1.47 & 0.84 & & 1.44 & 8 & \\
\hline & 2 & 2.70 & & 1.31 & 0.77 & & 1.31 & 8 & \\
\hline \multirow[t]{5}{*}{ Mouse } & Actual & 4.09 & 0.88 & & 0.19 & 0.01 & & 100 & 0 \\
\hline & Averaged & 9.61 & & 2.35 & 0.23 & & 1.21 & 100 & \\
\hline & 1 & 9.46 & & 2.32 & 0.22 & & 1.19 & 100 & \\
\hline & 2 & 9.78 & & 2.40 & 0.23 & & 1.22 & 100 & \\
\hline & 3 & 9.76 & & 2.39 & 0.23 & & 1.23 & 100 & \\
\hline
\end{tabular}


CYP2C and CYP2B, respectively. Cats were the only species appreciably sensitive to $\mathrm{CBP}$ - the CYP2B6 inhibitor-but considering the lack of CYP2B detected in the Western blot, it seems likely that CBP has a different $\mathrm{P} 450$ isozyme target in cats from that of the other species. No tested inhibitor completely ablated CP metabolism activity in humans, cats, or mice. In contrast, dog microsomal metabolism of $4 \mathrm{OHCP}$ is almost completely inhibited by fluconazole. Treatment with the canine CYP2C-specific inhibitor, sulfaphenzole, only slightly recapitulated the phenomenon observed with fluconazole. There was no observed impact of $4 \mathrm{OHCP}$ production when dog microsomes were treated with CYP2B inhibitors. The results propose the conclusion that CYP2C seems more significant than CYP2B in the metabolism of $\mathrm{CP}$ to $4 \mathrm{OHCP}$.

This finding is at odds with what has been published previously. The results from a recent study identified three important $\mathrm{P} 450$ active site residues that contribute to $\mathrm{CP}$ binding and recognition and that the dog ortholog (CYP2B11) contains mutations in these residue locations that renders it one of the most efficient enzymes at catalyzing $\mathrm{CP}$ hydroxylation (Chen et al., 2004). Rational engineering studies of CYP2B6 identified a residue substitution, L264F, that confers greater stability and metabolic activity to human CYP2B6 (Kumar et al., 2007). This phenylalanine residue is also found within the dog, cat, and mouse CYP2B protein sequences. Moreover, as a test of CYP2B and its role in $\mathrm{CP}$ bioactivation, gliosarcoma cells stably transfected with rat CYP2B1 became significantly more sensitive to $4 \mathrm{OHCP}$ and were capable of catalyzing CP bioactivation (Chen and Waxman, 1995). All these data tell a story that the CYP2B isozyme is significant for $4 \mathrm{OHCP}$ formation. The data presented in Fig. 5B, demonstrating a significant correlation between $V_{\max }$ and relative CYP2B expression, suggest the same. It is important to note that the mathematical expression for $V_{\max }=k_{c a t} *$ [enzyme $]_{\text {total }}$ contains a species-dependent apparent rate constant $\left(k_{c a t}\right)$ that for a multienzyme system represents the contribution of each enzyme involved. A direct comparison between $V_{\max }$ and CYP2B expression is thus inappropriate, but a generalized interpretation would suggest not only that the apparent $k_{\text {cat }}$ for CP transformation follows a trend among the species, but also that it appears to be influenced by CYP2B expression. Thus, considering published data, we favor a conclusion that CYP2C is a critical factor alongside CYP2B in determining $\mathrm{CP}$ bioactivation, particularly in canines.

Incorporating microsomal-derived Michaelis-Menten parameters into a semiphysiologic PK model using metabolism as the only form of clearance indicates the significance of CP metabolism in its overall PK profile. For the three animal species examined (dog, cat, and mouse), the simulation predicted half-lives and AUCs comparable to clinical data between microsomal sources. This observation supports the clinical applicability of microsome-obtained metabolism parameters for these species but emphasizes the importance of small changes in blood flow to the liver rather than metabolic parameters as the driver of PK variability. In humans, the model generally underestimated overall $\mathrm{CP}$ exposure and slightly overestimated the half-life. Unlike dog, cat, and mouse microsomes, different batches of human microsomes exhibited remarkably different simulated PK when incorporated into the model. This is due to the significantly lower rate of metabolism in humans, which causes CP to behave as a low liver extraction drug rather than high, as observed in the nonhuman species. For this reason, small changes in metabolic parameters will significantly influence human CP PK in vivo, whereas nonhuman species are more significantly influenced by blood flow to the liver. Based on the two human CP PK studies used for comparison, $\mathrm{H} 3$ exhibited the most representative metabolic parameters of the patient population and parameters obtained from this source could be scaled accurately for in vivo simulation.

The human simulations compared with clinical PK indicate the potential application of microsomes to predict metabolism yet emphasize the variability that may be observed in vivo owing to alterations in metabolic parameters. The simulated human half-lives, although slightly overestimated compared with the two studies, still fit within the range of observed $\mathrm{CP}$ half-lives compared with scores of PK studies (3.2-12.5 hours) (de Jonge et al., 2005), albeit near the lower end of that range.

These conclusions present an important view of differential CP metabolism in animals and humans and provide new insight to support the significance of multiple P450 isozymes in the hepatic bioactivation and clearance of $\mathrm{CP}$. This study also demonstrates the utility of in vitro metabolic characterization and that such data are crucial to understanding CP PK in humans, dogs, cats, and mice.

\section{Authorship Contributions}

Participated in research design: Ramirez, Gustafson.

Conducted experiments: Ramirez, Conger, Aradi.

Contributed new reagents or analytic tools: Ramirez, Collins.

Performed data analysis: Ramirez, Collins.

Wrote or contributed to the writing of the manuscript: Ramirez, Collins, Aradi, Gustafson.

\section{References}

Ahmed AR and Hombal SM (1984) Cyclophosphamide (Cytoxan): a review on relevant pharmacology and clinical uses. J Am Acad Dermatol 11:1115-1126.

Anderson LW, Chen TL, Colvin OM, Grochow LB, Collins JM, Kennedy MJ, and Strong JM (1996) Cyclophosphamide and 4-hydroxycyclophosphamide/aldophosphamide kinetics in patients receiving high-dose cyclophosphamide chemotherapy. Clin Cancer Res 2:1481-1487.

Back DJ, Tjia JF, Karbwang J, and Colbert J (1988) In vitro inhibition studies of tolbutamide hydroxylase activity of human liver microsomes by azoles, sulphonamides and quinolines. $\mathrm{BrJ}$ Clin Pharmacol 26:23-29.

Bagley CM, Jr, Bostick FW, and DeVita VT, Jr (1973) Clinical pharmacology of cyclophosphamide. Cancer Res 33:226-233.

Barter ZE, Bayliss MK, Beaune PH, Boobis AR, Carlile DJ, Edwards RJ, Houston JB, Lake BG, Lipscomb JC, Pelkonen OR, et al. (2007) Scaling factors for the extrapolation of in vivo metabolic drug clearance from in vitro data: reaching a consensus on values of human microsomal protein and hepatocellularity per gram of liver. Curr Drug Metab 8:33-45.

Bernhardt R (2006) Cytochromes P450 as versatile biocatalysts. J Biotechnol 124:128-145.

Boddy AV and Yule SM (2000) Metabolism and pharmacokinetics of oxazaphosphorines. Clin Pharmacokinet 38:291-304

Brown RP, Delp MD, Lindstedt SL, Rhomberg LR, and Beliles RP (1997) Physiological parameter values for physiologically based pharmacokinetic models. Toxicol Ind Health 13:407-484.

Carlile DJ, Hakooz N, Bayliss MK, and Houston JB (1999) Microsomal prediction of in vivo clearance of CYP2C9 substrates in humans. Br J Clin Pharmacol 47:625-635.

Chen CS, Lin JT, Goss KA, He YA, Halpert JR, and Waxman DJ (2004) Activation of the anticancer prodrugs cyclophosphamide and ifosfamide: identification of cytochrome P450 2B enzymes and site-specific mutants with improved enzyme kinetics. Mol Pharmacol 65: $1278-1285$.

Chen L and Waxman DJ (1995) Intratumoral activation and enhanced chemotherapeutic effect of oxazaphosphorines following cytochrome P-450 gene transfer: development of a combined chemotherapy/cancer gene therapy strategy. Cancer Res 55:581-589.

Chen TL, Passos-Coelho JL, Noe DA, Kennedy MJ, Black KC, Colvin OM, and Grochow LB (1995) Nonlinear pharmacokinetics of cyclophosphamide in patients with metastatic breast cancer receiving high-dose chemotherapy followed by autologous bone marrow transplantation. Cancer Res 55:810-816.

de Jonge ME, Huitema AD, Rodenhuis S, and Beijnen JH (2005) Clinical pharmacokinetics of cyclophosphamide. Clin Pharmacokinet 44:1135-1164.

Eagling VA, Tjia JF, and Back DJ (1998) Differential selectivity of cytochrome P450 inhibitors against probe substrates in human and rat liver microsomes. Br J Clin Pharmacol 45:107-114. Emadi A, Jones RJ, and Brodsky RA (2009) Cyclophosphamide and cancer: golden anniversary Nat Rev Clin Oncol 6:638-647.

Garrett LD, Thamm DH, Chun R, Dudley R, and Vail DM (2002) Evaluation of a 6-month chemotherapy protocol with no maintenance therapy for dogs with lymphoma. $J$ Vet Intern Med 16:704-709.

Gibhard L, Pravin K, Abay E, Wilhelm A, Swart K, Lawrence N, Khoury R, van der Westhuizen J, Smith $\mathrm{P}$, and Wiesner L (2016) In vitro and in vivo pharmacokinetics of aminoalkylated diarylpropanes NP085 and NP102. Antimicrob Agents Chemother 60:3065-3069.

Groehler A, IV, Villalta PW, Campbell C, and Tretyakova N (2016) Covalent DNA-protein crosslinking by phosphoramide mustard and nornitrogen mustard in human cells. Chem Res Toxicol 29:190-202.

Gunawardena J (2014) Models in biology: 'accurate descriptions of our pathetic thinking'. BMC Biol 12:29.

Heikkinen AT, Friedlein A, Lamerz J, Jakob P, Cutler P, Fowler S, Williamson T, Tolando R, Lave T, and Parrott N (2012) Mass spectrometry-based quantification of CYP enzymes to establish in vitro/in vivo scaling factors for intestinal and hepatic metabolism in beagle dog. Pharm Res 29:1832-1842.

Huang Z, Roy P, and Waxman DJ (2000) Role of human liver microsomal CYP3A4 and CYP2B6 in catalyzing N-dechloroethylation of cyclophosphamide and ifosfamide. Biochem Pharmacol 59:961-972.

Huitema A, Tibben M, Kerbusch T, Kettenes-van den Bosch J, Rodenhuis R, and Beijnen JH (2000) High performance liquid chromatographic determination of the stabilized cyclophosphamide 
metabolite 4-hydroxycyclophosphamide in plasma and red blood cells. J Liq Chromatogr Relat Technol 23:1725-1744.

Hutzler JM and Tracy TS (2002) Atypical kinetic profiles in drug metabolism reactions. Drug Metab Dispos 30:355-362.

Jia L and Liu X (2007) The conduct of drug metabolism studies considered good practice (II): in vitro experiments. Curr Drug Metab 8:822-829.

Korhonen LE, Turpeinen M, Rahnasto M, Wittekindt C, Poso A, Pelkonen O, Raunio H, and Juvonen RO (2007) New potent and selective cytochrome P450 2B6 (CYP2B6) inhibitors based on three-dimensional quantitative structure-activity relationship (3D-QSAR) analysis. $\mathrm{Br} \mathrm{J}$ Pharmacol 150:932-942.

Kumar S, Zhao Y, Sun L, Negi SS, Halpert JR, and Muralidhara BK (2007) Rational engineering of human cytochrome P450 2B6 for enhanced expression and stability: importance of a Leu264$>$ Phe substitution. Mol Pharmacol 72:1191-1199.

Kunze KL, Wienkers LC, Thummel KE, and Trager WF (1996) Warfarin-fluconazole. I. Inhibition of the human cytochrome P450-dependent metabolism of warfarin by fluconazole: in vitro studies. Drug Metab Dispos 24:414-421.

Kuroha M, Kuze Y, Shimoda M, and Kokue E (2002) In vitro characterization of the inhibitory effects of ketoconazole on metabolic activities of cytochrome P-450 in canine hepatic microsomes. Am J Vet Res 63:900-905.

Lautier T, Urban P, Loeper J, Jezequel L, Pompon D, and Truan G (2016) Ordered chimerogenesis applied to CYP2B P450 enzymes. Biochim Biophys Acta 1860:1395-1403.

Li F, Patterson AD, Höfer CC, Krausz KW, Gonzalez FJ, and Idle JR (2010) Comparative metabolism of cyclophosphamide and ifosfamide in the mouse using UPLC-ESI-QTOFMS-based metabolomics. Biochem Pharmacol 80:1063-1074.

Meijer DKF and van der Sluijs P (1989) Covalent and noncovalent protein binding of drugs: implications for hepatic clearance, storage, and cell-specific drug delivery. Pharm Res 6:105-118.

Miners JO and Birkett DJ (1998) Cytochrome P4502C9: an enzyme of major importance in human drug metabolism. Br J Clin Pharmacol 45:525-538.

Moghe A, Ghare S, Lamoreau B, Mohammad M, Barve S, McClain C, and Joshi-Barve S (2015) Molecular mechanisms of acrolein toxicity: relevance to human disease. Toxicol Sci 143 242-255.

Niwa T, Shiraga T, and Takagi A (2005) Effect of antifungal drugs on cytochrome P450 (CYP) 2C9, CYP2C19, and CYP3A4 activities in human liver microsomes. Biol Pharm Bull 28:1805-1808.

Okamatsu G, Komatsu T, Ono Y, Inoue H, Uchide T, Onaga T, Endoh D, Kitazawa T, Hiraga T, Uno Y, et al. (2017) Characterization of feline cytochrome P450 2B6. Xenobiotica 47:93-102.

Pearce RE, McIntyre CJ, Madan A, Sanzgiri U, Draper AJ, Bullock PL, Cook DC, Burton LA, Latham J, Nevins C, et al. (1996) Effects of freezing, thawing, and storing human liver microsomes on cytochrome P450 activity. Arch Biochem Biophys 331:145-169.

Penel N, Adenis A, and Bocci G (2012) Cyclophosphamide-based metronomic chemotherapy: after 10 years of experience, where do we stand and where are we going? Crit Rev Oncol Hematol 82: $40-50$.

Perez Jimenez TE, Mealey KL, Schnider D, Grubb TL, Greene SA, and Court MH (2018) Identification of canine cytochrome P-450s (CYPs) metabolizing the tramadol (+)-M1 and (+)-M2 metabolites to the tramadol (+)-M5 metabolite in dog liver microsomes. $J$ Vet Pharmacol Ther 41:815-824.

Ren S, Yang JS, Kalhorn TF, and Slattery JT (1997) Oxidation of cyclophosphamide to 4-hydroxycyclophosphamide and deschloroethylcyclophosphamide in human liver microsomes. Cancer Res 57:4229-4235.

Rodriguez-Antona C and Ingelman-Sundberg M (2006) Cytochrome P450 pharmacogenetics and cancer. Oncogene 25:1679-1691.

Roy P, Yu LJ, Crespi CL, and Waxman DJ (1999) Development of a substrate-activity based approach to identify the major human liver P-450 catalysts of cyclophosphamide and ifosfamide activation based on cDNA-expressed activities and liver microsomal P-450 profiles. Drug Metab Dispos 27:655-666.
Sakaeda T, Iwaki K, Kakumoto M, Nishikawa M, Niwa T, Jin JS, Nakamura T, Nishiguchi K, Okamura N, and Okumura K (2005) Effect of micafungin on cytochrome P450 3A4 and multidrug resistance protein 1 activities, and its comparison with azole antifungal drugs. $J$ Pharm Pharmacol 57:759-764.

Schindelin J, Arganda-Carreras I, Frise E, Kaynig V, Longair M, Pietzsch T, Preibisch S, Rueden C, Saalfeld S, Schmid B, et al. (2012) Fiji: an open-source platform for biological-image analysis. Nat Methods 9:676-682

Schneider CA, Rasband WS, and Eliceiri KW (2012) NIH Image to ImageJ: 25 years of image analysis. Nat Methods 9:671-675.

Smith R, Jones RD, Ballard PG, and Griffiths HH (2008) Determination of microsome and hepatocyte scaling factors for in vitro/in vivo extrapolation in the rat and dog. Xenobiotica 38: $1386-1398$.

Stevenson HC and Fauci AS (1980) Activation of human B lymphocytes. XII. Differential effects of in vitro cyclophosphamide on human lymphocyte subpopulations involved in B-cell activation. Immunology 39:391-397.

Stroda KA, Murphy JD, Hansen RJ, Brownlee L, Atencio EA, Gustafson DL, and Lana SE (2017) Pharmacokinetics of cyclophosphamide and 4-hydroxycyclophosphamide in cats after oral, intravenous, and intraperitoneal administration of cyclophosphamide. Am J Vet Res 78:862-866. Struck RF, Alberts DS, Horne K, Phillips JG, Peng YM, and Roe DJ (1987) Plasma pharmacokinetics of cyclophosphamide and its cytotoxic metabolites after intravenous versus oral administration in a randomized, crossover trial. Cancer Res 47:2723-2726.

Teske E, van Straten G, van Noort R, and Rutteman GR (2002) Chemotherapy with cyclophosphamide, vincristine, and prednisolone (COP) in cats with malignant lymphoma: new results with an old protocol. J Vet Intern Med 16:179-186.

Thelen K and Dressman JB (2009) Cytochrome P450-mediated metabolism in the human gut wall. J Pharm Pharmacol 61:541-558.

Tibbitts J (2003) Issues related to the use of canines in toxicologic pathology-issues with pharmacokinetics and metabolism. Toxicol Pathol 31(Suppl):17-24.

Uphoff C and Drexler H (2013) Detection of mycoplasma contaminations, in Basic Cell Culture Protocols (Helgason C and Miller C eds) pp 1-14, Humana Press, Totowa, NJ.

Visser M, Zaya MJ, Locuson CW, Boothe DM, and Merritt DA (2018) Comparison of predicted intrinsic hepatic clearance of 30 pharmaceuticals in canine and feline liver microsomes. Xen obiotica DOI: 10.1080/00498254.2018.1437933.

Vrbanac J and Slauter R (2013) ADME in drug discovery, in A Comprehensive Guide to Toxicology in Preclinical Drug Development (Faqi AS ed) pp 3-30, Elsevier Inc., Amsterdam.

Warry E, Hansen RJ, Gustafson DL, and Lana SE (2011) Pharmacokinetics of cyclophosphamide after oral and intravenous administration to dogs with lymphoma. J Vet Intern Med 25:903-908.

Xie HJ, Yasar U, Lundgren S, Griskevicius L, Terelius Y, Hassan M, and Rane A (2003) Role of polymorphic human CYP2B6 in cyclophosphamide bioactivation. Pharmacogenomics $J$ 3: $53-61$.

Yamazaki H, Inoue K, Turvy CG, Guengerich FP, and Shimada T (1997) Effects of freezing, thawing, and storage of human liver samples on the microsomal contents and activities of cytochrome P450 enzymes. Drug Metab Dispos 25:168-174.

Zanger UM and Schwab M (2013) Cytochrome P450 enzymes in drug metabolism: regulation of gene expression, enzyme activities, and impact of genetic variation. Pharmacol Ther 138: 103-141.

Address correspondence to: Dominique A. Ramirez, Robert and Mary Flint Animal Cancer Center, Colorado State University, 200 W Lake St., 1620 Campus Delivery, 300 W Drake Road, Fort Collins, CO, 80523. E-mail: mando.ramirez@ colostate.edu 